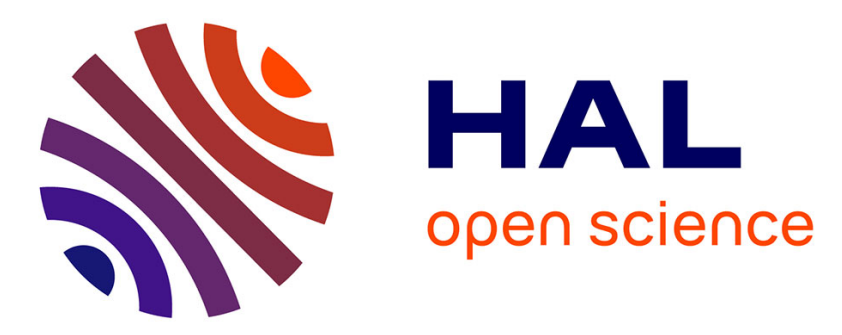

\title{
Electron density estimations derived from spacecraft potential measurements on Cluster in tenuous plasma regions
}

\author{
A Pedersen, B Lybekk, M André, E Eriksson, A. Masson, M S Mozer, A \\ Lindqvist, Pierrette Décréau, I Dandouras, J.A Sauvaud, et al.
}

\section{To cite this version:}

A Pedersen, B Lybekk, M André, E Eriksson, A. Masson, et al.. Electron density estimations derived from spacecraft potential measurements on Cluster in tenuous plasma regions. Journal of Geophysical Research Space Physics, 2008, 113 (A7), pp.7-33. 10.1029/2007JA012636 . insu-01408701

\section{HAL Id: insu-01408701 \\ https://hal-insu.archives-ouvertes.fr/insu-01408701}

Submitted on 5 Dec 2016

HAL is a multi-disciplinary open access archive for the deposit and dissemination of scientific research documents, whether they are published or not. The documents may come from teaching and research institutions in France or abroad, or from public or private research centers.
L'archive ouverte pluridisciplinaire HAL, est destinée au dépôt et à la diffusion de documents scientifiques de niveau recherche, publiés ou non, émanant des établissements d'enseignement et de recherche français ou étrangers, des laboratoires publics ou privés. 


\title{
Electron density estimations derived from spacecraft potential measurements on Cluster in tenuous plasma regions
}

\author{
A. Pedersen, ${ }^{1}$ B. Lybekk, ${ }^{1}$ M. André, ${ }^{2}$ A. Eriksson, ${ }^{2}$ A. Masson, ${ }^{3}$ F. S. Mozer, ${ }^{4}$ \\ P.-A. Lindqvist, ${ }^{5}$ P. M. E. Décréau, ${ }^{6}$ I. Dandouras, ${ }^{7}$ J.-A. Sauvaud, ${ }^{7}$ A. Fazakerley, ${ }^{8}$ \\ M. Taylor, ${ }^{3}$ G. Paschmann, ${ }^{9}$ K. R. Svenes, ${ }^{10}$ K. Torkar, ${ }^{11}$ and E. Whipple ${ }^{12}$ \\ Received 10 July 2007; revised 19 September 2007; accepted 16 October 2007; published 2 May 2008.
}

[1] Spacecraft potential measurements by the EFW electric field experiment on the Cluster satellites can be used to obtain plasma density estimates in regions barely accessible to other type of plasma experiments. Direct calibrations of the plasma density as a function of the measured potential difference between the spacecraft and the probes can be carried out in the solar wind, the magnetosheath, and the plasmashere by the use of CIS ion density and WHISPER electron density measurements. The spacecraft photoelectron characteristic (photoelectrons escaping to the plasma in current balance with collected ambient electrons) can be calculated from knowledge of the electron current to the spacecraft based on plasma density and electron temperature data from the above mentioned experiments and can be extended to more positive spacecraft potentials by CIS ion and the PEACE electron experiments in the plasma sheet. This characteristic enables determination of the electron density as a function of spacecraft potential over the polar caps and in the lobes of the magnetosphere, regions where other experiments on Cluster have intrinsic limitations. Data from 2001 to 2006 reveal that the photoelectron characteristics of the Cluster spacecraft as well as the electric field probes vary with the solar cycle and solar activity. The consequences for plasma density measurements are addressed. Typical examples are presented to demonstrate the use of this technique in a polar cap/lobe plasma.

Citation: Pedersen, A., et al. (2008), Electron density estimations derived from spacecraft potential measurements on Cluster in tenuous plasma regions, J. Geophys. Res., 113, A07S33, doi:10.1029/2007JA012636.

\section{Introduction}

[2] The four Cluster spacecraft, in operation from early 2001 in a high inclination orbit, have provided data over nearly half of the 11-year solar cycle. The orbits have perigees near $4.0 \mathrm{R}_{\mathrm{E}}$ and apogees near $19.7 \mathrm{R}_{\mathrm{E}}$. Apogees are in the magnetotail from approximately beginning of July

\footnotetext{
${ }^{1}$ Department of Physics, University of Oslo, Oslo, Norway.

${ }^{2}$ Swedish Institute of Space Physics, Uppsala, Sweden.

${ }^{3}$ RSSD, ESTEC, Noordwijk, Netherlands.

${ }^{4}$ Space Science Laboratory, University of California, Berkeley, California, USA.

${ }^{5}$ Division of Plasma Physics, Alfven Laboratory, Royal Institute of Technology, Stockholm, Sweden.

${ }^{6}$ Laboratoire de Physique et Chimie de l'Environnement, LPCE/CNRS, Orléans, France.

${ }^{7} \mathrm{CESR} / \mathrm{CNRS}$, Toulouse, France.

${ }^{8}$ Department of Physics, Mullard Space Science Laboratory, University College London, Dorking, UK.

${ }^{9}$ MPI fur Extraterrestrische Physik, Garching, Germany.

${ }^{10}$ Division of Electronics, Norwegian Defence Research Establishment, Kjeller, Norway.

${ }^{11}$ Space Research Institute, Austrian Academy of Sciences, Graz, Austria.

${ }^{12}$ Geophysics Department, University of Washington, Seattle, Washington, USA.
}

Copyright 2008 by the American Geophysical Union. 0148-0227/08/2007JA012636 to end of October, and the high inclination orbit makes it possible to obtain data in the tenuous plasma of the lobes at large distances from the plasma sheet not reached on previous missions. Deriving plasma density estimates from spacecraft potential measurements in the magnetosphere is only possible when a spacecraft is equipped with sufficiently conductive surfaces. Another necessary condition is that the spacecraft carries an electric field experiment with probes deployed to large distances from the spacecraft and that the probes are electronically controlled to be close to their local plasma potential and thereby can serve as a potential reference. The technique relies on calibration by other experiments measuring plasma density and, once calibrated, provides easily accessible, high time resolution information.

[3] In the magnetosphere the spacecraft potential is determined by the current balance between escaping photoelectrons and collected ambient electrons. For plasma conditions to be considered in this paper, the maximum photoelectron current is larger than the electron current from the plasma. A current balance is in this case achieved by a positive spacecraft, where a fraction of the emitted photoelectrons at lower energies are attracted back to the positive spacecraft, and a fraction at higher energies will escape and balance the collected ambient electrons. Ion currents are in comparison much smaller and can in the 
first instance be neglected. We will demonstrate that knowledge of the photoelectrons that escape from the spacecraft as a function of its potential (the spacecraft photoelectron characteristic) can be used for plasma density measurements. To estimate the photoelectron characteristic of a Cluster satellite, the following experiments on Cluster will be used for calibrations: Waves of High Frequency and Sounder for Probing of Electron Density by Relaxation (WHISPER). The experiment makes use of active sounding and monitoring of natural magnetoplasma waves in the $4-83 \mathrm{kHz}$ range to evaluate the thermal electron density [Décréau et al.,1997]; Cluster Ion Spectrometer (CIS) measures the full three-dimensional ion distribution of the major ion species from thermal energies to $40 \mathrm{keV} / \mathrm{e}$ [Rème et al., 2001]. Ion densities and velocities are important data products; Plasma Electron and Current Experiment (PEACE) measures the threedimensional velocity distribution of electrons in the $0.6-$ $36 \mathrm{keV}$ range [Johnstone et al., 1997]. Electron densities and temperatures are important data products; Electron Drift Instrument (EDI) measures the drift velocity of artificially injected $\sim 1 \mathrm{keV}$ electrons [Paschmann et al., 2001]. High current operations will move the Cluster spacecraft potential to more positive values in a tenuous plasma, and is used for calibrations; Active Spacecraft Potential Control (ASPOC). This experiment emits $\sim 6 \mathrm{keV}$ Indium ions to reduce the large positive potentials of Cluster in tenuous plasmas [Torkar et al., 2001]. Comparison of ASPOC and EFW data are used to check the electric characteristics of conductive surfaces on Cluster.

[4] Electric field measurements on Cluster are described by Gustafsson et al. [1997] and Eriksson et al. [2006] and will not be discussed further in this paper. Here, we will concentrate on the determination of the spacecraft potential and relate it to plasma density in the magnetosphere. Several previous studies have dealt with the spacecraft potential technique and have used it for studies in the magnetosphere [e.g., Pedersen, 1995; Escoubet et al., 1997; Laakso and Pedersen, 1998; Pedersen et al., 1998; Nakagawa et al., 2000; Scudder et al., 2000; Pedersen et al., 2001; Laakso et al., 2002; Thiébault et al., 2006] This paper is a follow-on to Pedersen et al. [2001], where the early spacecraft potential measurements on Cluster were described and its use for fast four-point measurements near the magnetopause was demonstrated.

[5] Electron densities from WHISPER and ion densities from CIS are in good agreement in the solar wind and the magnetosheath, and the connection between plasma density and the measured probe-spacecraft potential difference can be established. An analytic function, describing this connection, can be fitted to the data. Combination of this function with fast measurements of the spacecraft potential allows to get plasma density with a time resolution of $0.2 \mathrm{~s}$, compared to $4 \mathrm{~s}$ for direct electron or ion density measurements. A different approach is necessary in a more tenuous plasma with a more positive spacecraft potential. Part of the ion population may not reach the spacecraft, while ambient electrons to the spacecraft may be swamped by spacecraft photoelectrons. Moreover, WHISPER electron density determination may be upset by added density from spacecraft photoelectrons. The main part of this paper will be devoted to develop the photoelectron characteristic for the spacecraft up to potentials of $+(40-50) \mathrm{V}$ observed over the polar caps and in the lobes and plasma sheet boundary layer. Only approximate knowledge of the mean electron energy is required to get an approximate relation between spacecraft potential and plasma density in these regions.

[6] A list of symbols used is presented here for easy access: $A_{p}, A_{p h p}, I_{e p}, I_{p h p}$ probe total area, area projected to the Sun, electron current from plasma to probe, photoelectrons escaping from a probe to the plasma near the probe

$I_{b}$

$\mathrm{I}_{\text {pha }}$

$f_{p} I_{\text {php }}$

$f_{a} I_{\text {pha }}$

$\mathrm{I}_{+}$ bias current driving electrons from the spacecraft to the probes current of photoelectrons escaping from preamplifier box and guard fraction of $\mathrm{I}_{\text {php }}$ to the ambient plasma fraction of $\mathrm{I}_{\text {pha }}$ to the ambient plasma current of $\sim 6 \mathrm{keV}$ Indium ions emitted by ASPOC

$A_{s}, A_{b}, I_{e s}, I_{e b}$ total areas of spacecraft body and booms and their currents of electrons collected from the plasma

$I_{e S}=I_{e s}+I_{e b}$ the electrons collected by the probes and their supports is negligible in comparison

$A_{\text {phs }}, A_{p h b}$,

$\mathrm{I}_{\mathrm{phs}}, \mathrm{I}_{\mathrm{phb}}$

$\mathrm{I}_{\mathrm{phS}}=\mathrm{I}_{\mathrm{phs}}+$

$\mathrm{I}_{\text {phb }}+4\left(\mathrm{f}_{\mathrm{p}} \mathrm{I}_{\mathrm{php}}+\right.$

$\mathrm{f}_{\mathrm{a}} \mathrm{I}_{\text {pha }}$ )

$\lambda_{\mathrm{D}}$

$\mathrm{N}_{\mathrm{e}}($ EFW $)$

$\mathrm{N}_{\mathrm{e}}(\mathrm{WHI})$

$\mathrm{N}_{\mathrm{e}}$ (PEACE)

$\mathrm{N}_{+}$(CIS)

$\mathrm{V}_{+}(\mathrm{CIS})$

$\mathrm{V}_{\mathrm{e}}$

\section{$\mathrm{V}_{\mathrm{p}}$}

$V_{n p}$

$\mathrm{V}_{\mathrm{s}}$

$\mathrm{V}_{\mathrm{os}}$

$\mathrm{V}_{\mathrm{r}}$

$R_{s}$ areas of spacecraft body and booms projected to the Sun and their currents of photoelectrons to the plasma total current of photoelectrons to the plasma from body, booms and probe systems

Debye length electron density measured by EFW electron density measured by WHISPER

electron density measured by PEACE ion density measured by CIS ion mean energy $\mathrm{kT}_{\mathrm{e}} / \mathrm{e} . \mathrm{T}_{\mathrm{e}}(\mathrm{PEACE})$ is the electron mean temperature probe potential potential near probe potential of the outer surfaces of the spacecraft plasma potential at the position of the spacecraft potential of electric reference point inside the spacecraft resistance between the spacecraft inner structure and the outer surfaces at a potential $\mathrm{V}_{\mathrm{s}}$

$\mathrm{SC} 1, \mathrm{SC} 2, \quad$ symbols for the four Cluster spacecraft

$\mathrm{SC} 3, \mathrm{SC} 4$

\section{Potentials of Electric Field Probes and the Spacecraft}

\subsection{EFW Electric Field Experiment}

[7] Each Cluster spacecraft has an Electric Fields and Waves experiment (EFW) [Gustafsson et al., 1997; Pedersen 


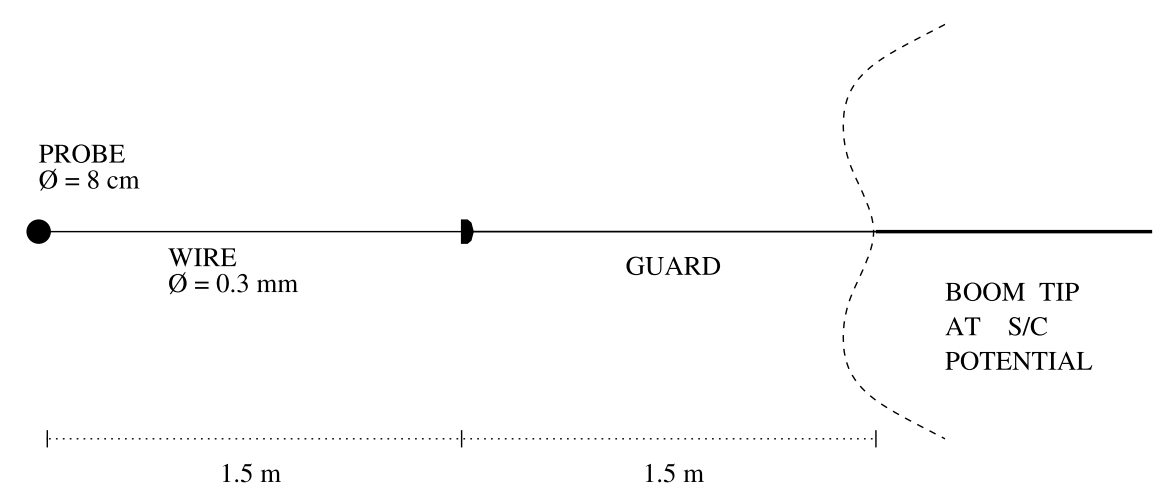

Figure 1. Sketch of a Cluster electric field antenna. An $8 \mathrm{~cm}$ diameter spherical probe is extended on a thin $0.3 \mathrm{~mm}$ diameter wire $1.5 \mathrm{~m}$ from the preamplifier housing. The purpose is to approach conditions for an undisturbed spherical probe in the plasma. A guard, at a negative potential, is placed between the preamplifier housing and the long radial boom.

et al., 1998] with four spherical probes and preamplifiers located at the tips of four radial wire booms spinning with the spacecraft at $0.25 \mathrm{~Hz}$. The two probe pairs have a baseline of $88 \mathrm{~m}$ tip-to-tip that allows for measuring two orthogonal electric field components in the spin plane. Electric field measurements require that the probes are controlled to be close to the local plasma potential near each probe. This makes it possible to use the probes as a potential reference for the spacecraft. The probe potential is determined by the current balance between escaping photoelectrons and collected electrons. The latter is composed of ambient electrons and a bias current $\left(\mathrm{I}_{\mathrm{b}}\right)$ from a high impedance current source in the spacecraft. Figure 1 is a sketch of one of the Cluster electric field probe systems, which consists of an $8 \mathrm{~cm}$ diameter sphere extended on a $0.3 \mathrm{~mm}$ diameter $1.5 \mathrm{~m}$ long wire connected to a preamplifier at the tip of the wire boom. The outer $1.5 \mathrm{~m}$ of the braid of the wire boom is a guard controlled to be at a potential of minus $6 \mathrm{~V}$ relative to the probe in order to limit the influence of photoelectrons from the spacecraft boom tip on the spacecraft side of the guard.
This tip is at the same positive potential as the spacecraft. In addition, the probe preamplifier housing is controlled to be at plus $1 \mathrm{~V}$ relative to the probe to limit photoelectrons from the preamplifier housing to come to the probe.

[8] Figure 2 illustrates how a probe will achieve a potential $\left(\mathrm{V}_{\mathrm{p}}\right)$ close to its local plasma potential $\left(\mathrm{V}_{\mathrm{np}}\right)$. We will in the following explain that $\mathrm{V}_{\mathrm{np}}$ will increase when the spacecraft potential increases and will be positive relative to the ambient plasma potential $\left(\mathrm{V}_{0}\right)$ at some distance from the probes. All photoelectrons emitted from the surface of a probe will escape $\left(\mathrm{I}_{\mathrm{php} 0}\right)$ when $\left(\mathrm{V}_{\mathrm{p}}-\mathrm{V}_{\mathrm{np}}\right)<0$. For positive values of $\left(V_{p}-V_{n p}\right)$, photoelectrons with energies below $\mathrm{e}\left(\mathrm{V}_{\mathrm{p}}-\mathrm{V}_{\mathrm{np}}\right)$ will be attracted back to the probe and only escaping photoelectrons will be in current balance with collected ambient electrons $\left(\mathrm{I}_{\mathrm{ep}}\right)$ plus the bias current $\mathrm{I}_{\mathrm{b}}$. Ion currents are only a few percent of $\mathrm{I}_{\mathrm{ep}}$ except for extreme plasma flows in the solar wind or the plasma sheet. In the following we will assume that only electrons are involved in the current balance for spacecraft as well as probes. We will use the term electron current (opposite to the conventional

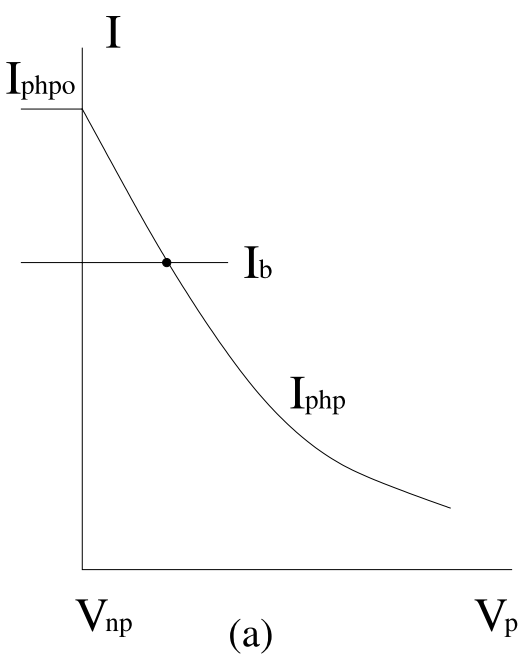

(a)

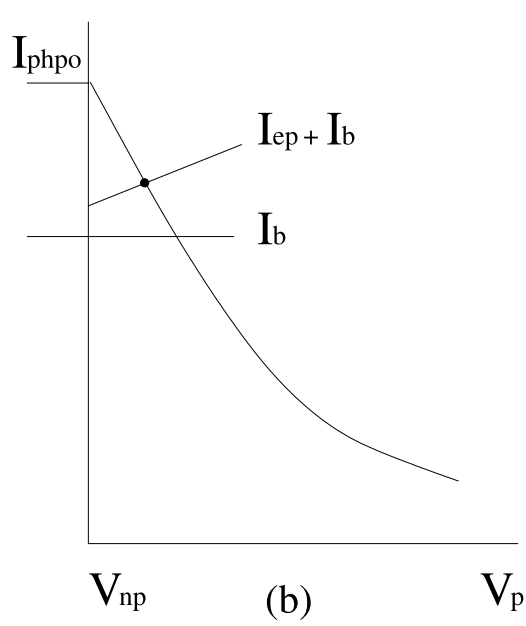

(b)

Figure 2. Illustration of the current balance of a probe. (a) In a tenuous plasma, the current generated by the photoelectrons, escaping from the probe to the plasma $\left(\mathrm{I}_{\mathrm{php}}\right)$, is balanced by the negative bias current $\left(\mathrm{I}_{\mathrm{b}}\right)$ which is forced on to the probe from the spacecraft. (b) In a more dense plasma, an ambient electron current $\left(\mathrm{I}_{\mathrm{ep}}\right)$ adds to the bias current so that $\mathrm{I}_{\mathrm{php}}=-\left(\mathrm{I}_{\mathrm{ep}}+\mathrm{I}_{\mathrm{b}}\right)$. 


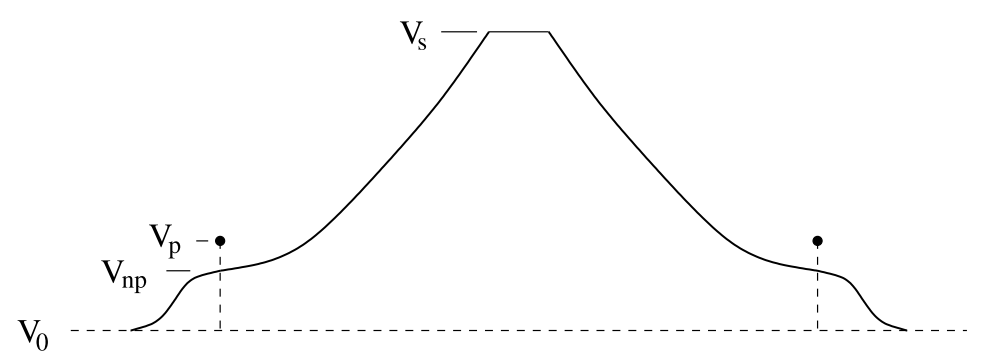

a)

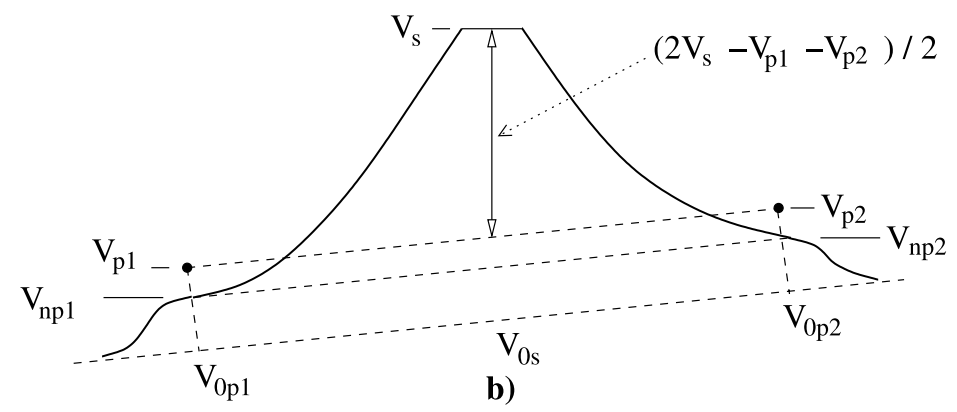

Figure 3. Potentials of the spacecraft $\left(\mathrm{V}_{\mathrm{s}}\right)$ and the probes $\left(\mathrm{V}_{\mathrm{p}}\right)$ versus radial distance in the spin plane of the electric field probes (see Figure 6). (a) Potentials for a plasma with a negligible electric field and a spacecraft at a potential $\mathrm{V}_{0}$ relative to the ambient plasma. The potential near the probes $\left(\mathrm{V}_{\mathrm{np}}\right)$ is influenced by the spacecraft and is approximately $19 \%$ of $\left(\mathrm{V}_{\mathrm{s}}-\mathrm{V}_{0}\right)$. (b) A situation when the ambient electric field exceeds a few $\mathrm{mVm}^{-1}$. It is then necessary to use two opposite probes to find $\left(\mathrm{V}_{\mathrm{s}}-\mathrm{V}_{0 \mathrm{~s}}\right)$, where $\mathrm{V}_{0 \mathrm{~s}}$ is the plasma potential at the location of the spacecraft.

direction). The probes are used as a potential reference for the spacecraft, and it is important to know $\mathrm{I}_{\mathrm{php}}$ in order to determine $\left(\mathrm{V}_{\mathrm{p}}-\mathrm{V}_{\mathrm{np}}\right)$ for a given setting of $\mathrm{I}_{\mathrm{b}}$. In a tenuous lobe plasma $\mathrm{I}_{\mathrm{b}} \gg \mathrm{I}_{\mathrm{ep}}$, and a current balance will be achieved between $I_{b}$ and $I_{\text {php }}$ (Figure 2a). In a more dense plasma, such as in the magnetosheath or the solar wind, $\mathrm{I}_{\mathrm{ep}}$ may be comparable to $\mathrm{I}_{\mathrm{b}}$, and the current balance in this case is between $\left(\mathrm{I}_{\mathrm{b}}+\mathrm{I}_{\mathrm{ep}}\right)$ and $\mathrm{I}_{\mathrm{php}}$, resulting in a reduction of $\left(\mathrm{V}_{\mathrm{p}}-\right.$ $\mathrm{V}_{\mathrm{np}}$ ) as illustrated in Figure $2 \mathrm{~b}$. The Debye length, $\lambda_{\mathrm{D}}$, in these regions is always much larger than the probe diameter, and $\mathrm{I}_{\mathrm{ep}}$ is a linear function of $\left(\mathrm{V}_{\mathrm{p}}-\mathrm{V}_{\mathrm{np}}\right)$ as explained in section 2.3. $\mathrm{I}_{\mathrm{b}}$, generated by a high impedance current source, does not vary with $\left(\mathrm{V}_{\mathrm{p}}-\mathrm{V}_{\mathrm{np}}\right)$.

\subsection{Spacecraft Potential}

[9] Cully et al. [2007] have carried out numerical calculation of the potential around Cluster, including booms and the probe systems. They found that the potential in the vicinity of the probes $\left(\mathrm{V}_{\mathrm{np}}\right)$ is driven by the positive boom tips and is approximately $19 \%$ of the spacecraft potential when the Debye length $\left(\lambda_{\mathrm{D}}\right)$ is larger than the probe-boom tip separation of $3 \mathrm{~m}$. A probe, controlled by $\mathrm{I}_{\mathrm{b}}$ to be at 1 to $2 \mathrm{~V}$ relative to $\mathrm{V}_{\mathrm{np}}$, will generate potentials of the order a fraction of a volt above $\mathrm{V}_{\mathrm{np}}$ at a few probe diameters. A probe can therefore function as a satisfactory measuring point in the much larger volume at a potential $V_{n p}$ when $I_{b}$ has a correct setting. Figure 3 a illustrates the potentials of $\mathrm{V}_{\mathrm{np}}, \mathrm{V}_{\mathrm{p}}$ and the satellite potential $\left(\mathrm{V}_{\mathrm{s}}\right)$ relative to the ambient plasma potential $\left(\mathrm{V}_{0}\right)$. In this case, $\mathrm{V}_{0}$ does not vary over the double probe distance. However, electric fields of tens of $\mathrm{mVm}^{-1}$ are observed in the magnetosphere, and the plasma potential difference between opposite probes can be several volts. It is therefore necessary to use measurements between the spacecraft and the two opposite probes to determine the parameter $1 / 2\left[\left(\mathrm{~V}_{\mathrm{s}}-\right.\right.$ $\left.\left.\mathrm{V}_{\mathrm{p} 1}\right)+\left(\mathrm{V}_{\mathrm{s}}-\mathrm{V}_{\mathrm{p} 2}\right)\right]=1 / 2\left(2 \mathrm{~V}_{\mathrm{s}}-\mathrm{V}_{\mathrm{p} 1}-\mathrm{V}_{\mathrm{p} 2}\right)$ which is the potential difference between $\mathrm{V}_{\mathrm{s}}$ and the midpoint between $\mathrm{V}_{\mathrm{p} 1}$ and $\mathrm{V}_{\mathrm{p} 2}$ as illustrated in Figure $3 \mathrm{~b}$. In the following we will refer to $1 / 2\left(2 \mathrm{~V}_{\mathrm{s}}-\mathrm{V}_{\mathrm{p} 1}-\mathrm{V}_{\mathrm{p} 2}\right)$ as $\left(\mathrm{V}_{\mathrm{s}}-\mathrm{V}_{\mathrm{p}}\right)$ and assume that $\left(\mathrm{V}_{\mathrm{p} 1}-\mathrm{V}_{\mathrm{np} 1}\right)=\left(\mathrm{V}_{\mathrm{p} 2}-\mathrm{V}_{\mathrm{np} 2}\right)=\left(\mathrm{V}_{\mathrm{p}}-\mathrm{V}_{\mathrm{np}}\right)$. Furthermore, we assume that $\left(\mathrm{V}_{\mathrm{np} 1}-\mathrm{V}_{0 \mathrm{p} 1}\right)=\left(\mathrm{V}_{\mathrm{np} 2}-\right.$ $\left.\mathrm{V}_{0 \mathrm{p} 2}\right)=0.19\left(\mathrm{~V}_{\mathrm{s}}-\mathrm{V}_{0 \mathrm{~s}}\right)$. The spacecraft potential $\left(\mathrm{V}_{\mathrm{s}}-\right.$ $\mathrm{V}_{0 \mathrm{~s}}$ ) can then be written:

$$
\begin{aligned}
\left(\mathrm{V}_{\mathrm{s}}-\mathrm{V}_{0 \mathrm{~s}}\right) & =\left(\mathrm{V}_{\mathrm{s}}-\mathrm{V}_{\mathrm{p}}\right)+\left(\mathrm{V}_{\mathrm{p}}-\mathrm{V}_{\mathrm{np}}\right)+0.19\left(\mathrm{~V}_{\mathrm{s}}-\mathrm{V}_{0 \mathrm{~s}}\right) \\
\mathrm{V}_{\mathrm{s}}-\mathrm{V}_{0 \mathrm{~s}} & =(1-0.19)^{-1}\left[\left(\mathrm{~V}_{\mathrm{s}}-\mathrm{V}_{\mathrm{p}}\right)+\left(\mathrm{V}_{\mathrm{p}}-\mathrm{V}_{\mathrm{np}}\right)\right] \\
& =1.23\left[\left(\mathrm{~V}_{\mathrm{s}}-\mathrm{V}_{\mathrm{p}}\right)+\left(\mathrm{V}_{\mathrm{p}}-\mathrm{V}_{\mathrm{np}}\right)\right]
\end{aligned}
$$

The PEACE experiment regularly observes accelerated cold electrons that can be photoelectrons returning to the spacecraft from the probes and/or cold ambient electrons [Szita et al., 2001]. Figure 4 shows samples of electron energies for a range of the measured parameter $\left(\mathrm{V}_{\mathrm{s}}-\mathrm{V}_{\mathrm{p}}\right)$ when Cluster was in a tenuous plasma over the northern polar cap. The acceleration potential of PEACE electrons is in fair agreement with $\left(\mathrm{V}_{\mathrm{s}}-\mathrm{V}_{0 \mathrm{~s}}\right)$ as a function of $\left(\mathrm{V}_{\mathrm{s}}-\mathrm{V}_{\mathrm{p}}\right)$ given in equation (1) assuming that $\left(\mathrm{V}_{\mathrm{p}}-\mathrm{V}_{\mathrm{np}}\right) \ll\left(\mathrm{V}_{\mathrm{s}}-\right.$ $\left.\mathrm{V}_{\mathrm{p}}\right)$. In equation (1) $\left(\mathrm{V}_{\mathrm{s}}-\mathrm{V}_{\mathrm{p}}\right)$ is a directly measured parameter. To derive $\left(\mathrm{V}_{\mathrm{s}}-\mathrm{V}_{0 \mathrm{~s}}\right),\left(\mathrm{V}_{\mathrm{p}}-\mathrm{V}_{\mathrm{np}}\right)$ needs to be determined. This is discussed in the next section. 


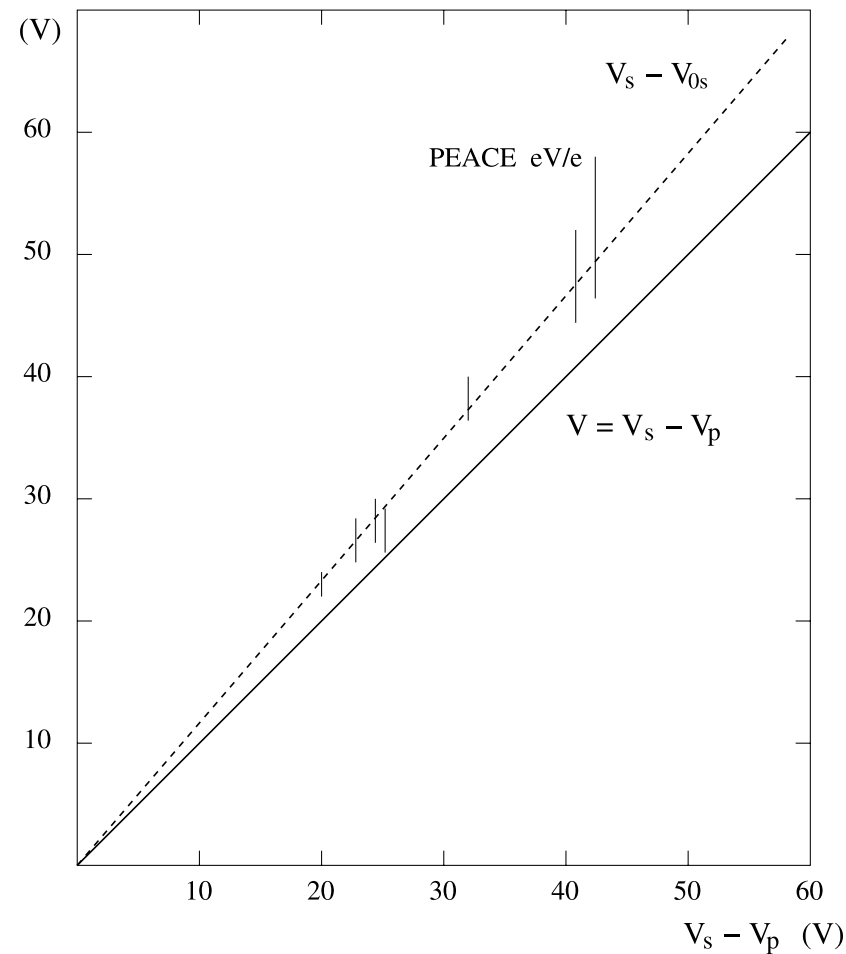

Figure 4. Measurements by PEACE on 14 August 2001 showing low-energy returning photoelectrons and possibly cold ambient electrons accelerated to approximately $25 \%$ above the measured potential difference $\left(\mathrm{V}_{\mathrm{s}}-\mathrm{V}_{\mathrm{p}}\right)$. (Equation (1) shows that the spacecraft potential is slightly more than $23 \%$ above $\left(V_{s}-V_{p}\right)$ when the probes are $1-2 \mathrm{~V}$ above their local plasma.)

\subsection{Electric Field Probes as a Potential Reference}

[10] Figure 5 illustrates how $\mathrm{I}_{\mathrm{php}}$ and $\mathrm{I}_{\mathrm{pha}}$, the currents of photoelectrons, having high enough energy to escape from a probe, its preamplifier box and its guard, will be split into parts $f_{p} I_{p h p}$ and $f_{a} I_{p h a}$ going to the plasma and the remaining parts $\left(1-f_{p}\right) I_{\text {php }}$ and $\left(1-f_{a}\right) I_{\text {pha }}$ being attracted back to the positive spacecraft boom and the spacecraft body. The parameters $f_{p}$ and $f_{a}$ will be reduced when the spacecraft goes more positive in a tenuous plasma and attracts more photoelectrons from the probe systems.

[11] Debye lengths $\left(\lambda_{\mathrm{D}}\right)$ are considerably larger than the diameter of the spherical probes for plasma conditions discussed in this paper. The ambient electron current to a spherical probe is then given by the well known formulae for the collection of electrons to a spherical body [Mott-Smith and Langmuir, 1926]:

$$
\mathrm{I}_{\mathrm{ep}}=\mathrm{I}_{\mathrm{ep} 0}\left[1+\left(\mathrm{V}_{\mathrm{p}}-\mathrm{V}_{\mathrm{np}}\right) / \mathrm{V}_{\mathrm{e}}\right]
$$

where $\mathrm{I}_{\mathrm{ep} 0}=\mathrm{C} \mathrm{N}_{\mathrm{e}} \mathrm{V}_{\mathrm{e}}^{1 / 2} \mathrm{~A}_{\mathrm{p}}, \mathrm{C}=2.68 \times 10^{-14} \mathrm{Am}^{3} \mathrm{~V}^{-1 / 2}, \mathrm{~N}_{\mathrm{e}}$ is the electron density in $\mathrm{m}^{-3}, \mathrm{~V}_{\mathrm{e}}=\mathrm{kT}_{\mathrm{e}} / \mathrm{e}$ in $\mathrm{V}$, and $\mathrm{A}_{\mathrm{p}}$ is the probe total area in $\mathrm{m}^{2}$.

[12] A fixed bias current $\left(\mathrm{I}_{\mathrm{b}}\right)$ to the probes add to $\mathrm{I}_{\mathrm{ep}}$. The probe potential, relative to its local plasma $\left(\mathrm{V}_{\mathrm{p}}-\mathrm{V}_{\mathrm{np}}\right)$ is determined by the current balance between electrons to the probe and photoelectrons escaping from the probe to the local plasma. The current of photoelectrons from the probe to the local plasma surrounding the probes can therefore be written:

$$
\mathrm{I}_{\mathrm{php}}=-\left(\mathrm{I}_{\mathrm{ep}}+\mathrm{I}_{\mathrm{b}}\right)
$$

In 2001 the maximum probe photoelectron current $\left(\mathrm{I}_{\mathrm{php} 0}\right)$ was estimated to be slightly above $300 \mathrm{nA}$ from measurements in a dense solar wind plasma (see Appendix A for details). In a tenuous plasma where $\mathrm{I}_{\mathrm{e}} \ll \mathrm{I}_{\mathrm{b}}$, it was expected to determine $\mathrm{I}_{\mathrm{php}}$ from stepping $\mathrm{I}_{\mathrm{b}}$ till $\mathrm{I}_{\mathrm{php} 0}$ was reached. However, $\mathrm{I}_{\mathrm{b}}$ stepping in 2001 , when $\left(\mathrm{V}_{\mathrm{s}}-\mathrm{V}_{\mathrm{p}}\right)$ was very positive, resulted in $\mathrm{I}_{\mathrm{php} 0} \approx 250 \mathrm{nA}$. A likely explanation of this difference is that for a more positive spacecraft more probe photoelectrons will be attracted back to the spacecraft, and $\mathrm{I}_{\text {php } 0}$ is reached for $\mathrm{I}_{\mathrm{b}}<\mathrm{I}_{\text {php } 0}$.

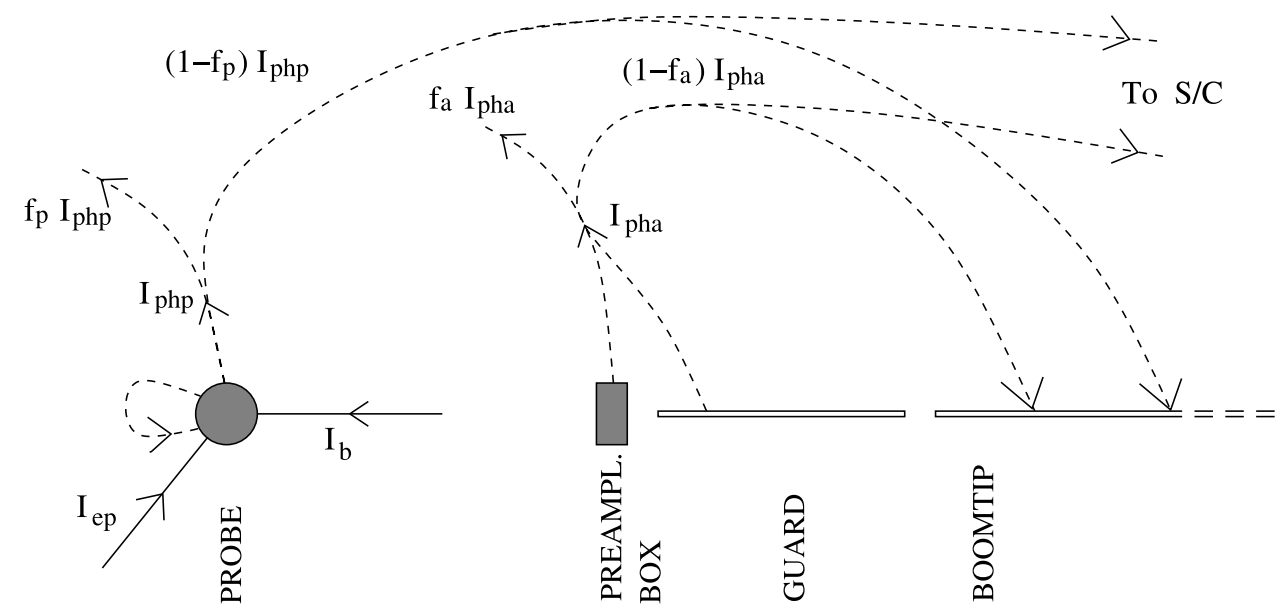

Figure 5. Illustration of the electrons collected by and leaving from the different parts of a Cluster electric field antenna. The current related to the ambient electrons collected by the probe $\left(\mathrm{I}_{\mathrm{ep}}\right)$ and the bias current $\left(\mathrm{I}_{\mathrm{b}}\right)$ from the spacecraft are symbolized by solid lines with arrows going to the probe. Currents related to photoelectrons escaping from the probe, the preamplifier box and the guard (dashed curves with arrows) are split into fractions that go to the plasma $\left[\mathrm{f}_{\mathrm{p}} \mathrm{I}_{\mathrm{php}}+\mathrm{f}_{\mathrm{a}} \mathrm{I}_{\mathrm{pha}}\right]$ and fractions $[(1-$ $\left.f_{p} I_{\text {php }}+\left(1-f_{a}\right) I_{\text {pha }}\right]$ returning to the spacecraft. 


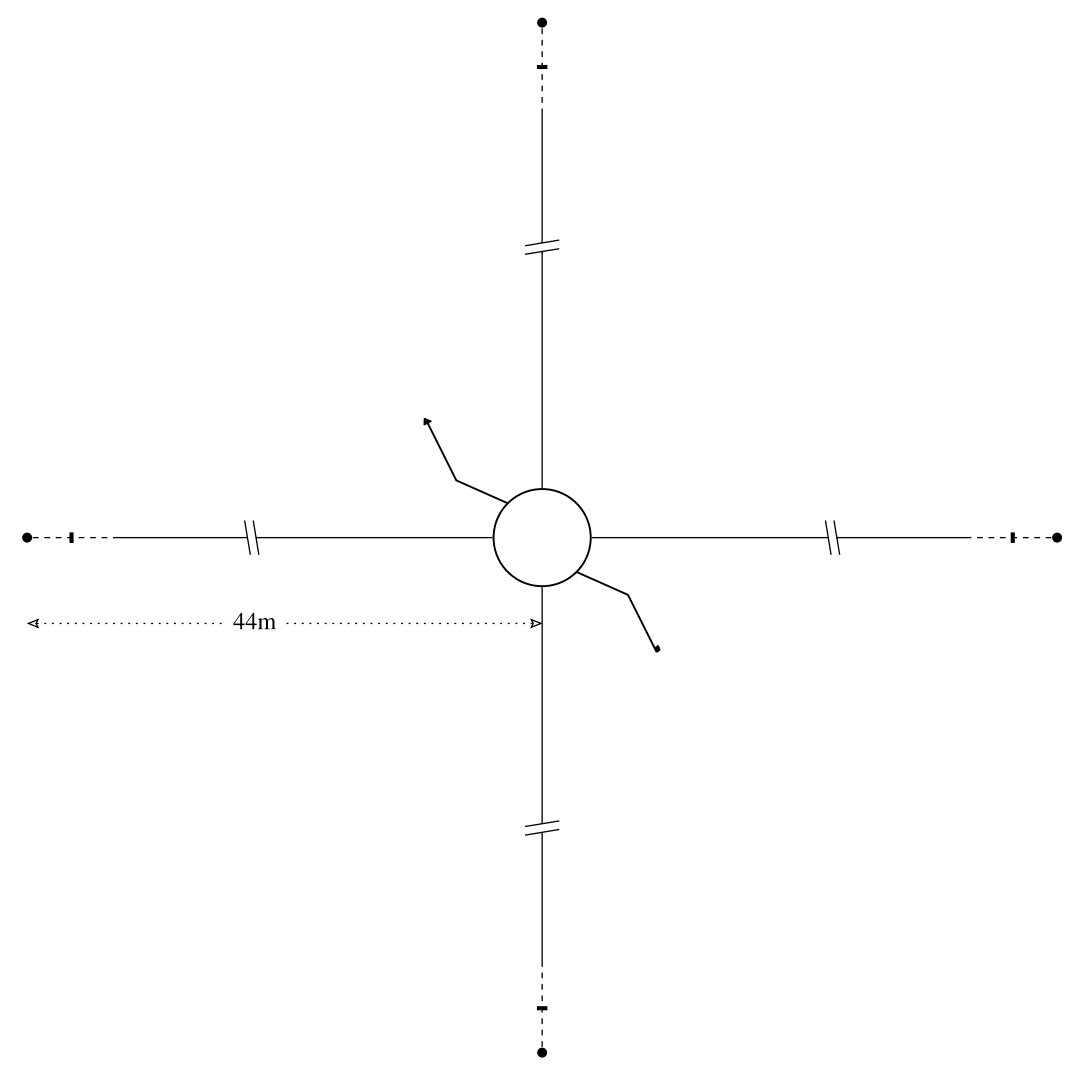

Figure 6. Sketch of a Cluster satellite with all booms deployed. The four orthogonal booms have the electric field probes mounted at their tips.

[13] Experiments to determine $\mathrm{I}_{\mathrm{php}}$ for 2006 are also presented in Appendix A and show that $\mathrm{I}_{\text {php }}$ was reduced from near solar maximum in 2001 to near solar minimum in 2006. Brace et al. [1988] found that $\mathrm{I}_{\mathrm{php}}$ for a Langmuir probe on Pioneer Venus varied with the parallel measurements of Lyman alpha radiation on the Solar Mesospheric Explorer satellite. $\mathrm{I}_{\mathrm{php}}$ had a maximum near solar maximum and was reduced to approximately $65 \%$ of this value near solar minimum. There are no continuous measurements of Lyman alpha radiation from the full Sun during the Cluster mission. However, we have found that the reduction of $\mathrm{I}_{\mathrm{php}}$ from 2001 to 2006 agrees with the findings of Brace et al. [1988]. We will in the following be particularly interested in $\left(\mathrm{V}_{\mathrm{p}}-\mathrm{V}_{\mathrm{np}}\right)$ in a tenuous plasma. Limits of $\left(\mathrm{V}_{\mathrm{p}}-\mathrm{V}_{\mathrm{np}}\right)$ in this plasma for $\mathrm{I}_{\mathrm{b}}=140 \mathrm{nA}$ is $(2.2 \pm 0.2) \mathrm{V}$ in 2001 and $(0.9 \pm 0.2) \mathrm{V}$ in 2006, as explained in Appendix A. This is still a satisfactory potential reference for the determination of the spacecraft photoelectron characteristic to large positive spacecraft potentials. $\mathrm{I}_{\mathrm{b}}=140 \mathrm{nA}$ has been used as a fixed value from June 2001 till June 2006 when $\mathrm{I}_{\mathrm{b}}$ was changed to $100 \mathrm{nA}$ in order to make sure that the probes would not be driven to negative potentials in the magnetosheath.

\section{Spacecraft Photoelectron Characteristic}

3.1. Current Balance Between Spacecraft Collected Electrons and Photoelectrons Escaping to the Plasma

[14] The spacecraft potential is determined by the balance between collected electrons and photoelectrons having high enough energy to escape to the plasma in the same way as described for the probes. This current balance can simply be written as follows:

$$
\mathrm{I}_{\mathrm{phS}}=-\mathrm{I}_{\mathrm{eS}}
$$

with $I_{\mathrm{phS}}$ the spacecraft photoelectron characteristic for the complete spacecraft, including the two short radial magnetometer booms and the four electric field probe systems on long wire booms. $\mathrm{I}_{\mathrm{eS}}$ is the ambient electron current collected by the spacecraft body and booms (see Figure 6). The electron collection by the probe systems is very small in comparison, and can be neglected in the estimate of $\mathrm{I}_{\mathrm{eS}}$.

[15] Each Cluster spacecraft has a cylindrical shape of $3.0 \mathrm{~m}$ diameter and $0.95 \mathrm{~m}$ height, that amounts to an area, $\mathrm{A}_{\mathrm{s}}$, of approximately $23 \mathrm{~m}^{2}$. The booms together have an area, $A_{b}$, of approximately $3 \mathrm{~m}^{2}$. We will assume that for $\lambda_{\mathrm{D}}$ larger than the Cluster platform radius, a Cluster spacecraft collects electrons like a sphere of $23 \mathrm{~m}^{2}$ surface and that equation (2) can be rewritten for the spacecraft by replacing $A_{p}$ with $A_{s}$. It is more difficult to find a good approximation for the electron collection by the four long wire booms and the two shorter booms. We have chosen to estimate the electron collection of the booms by assuming that they are parts of infinitely long cylinders in plasma with $\lambda_{\mathrm{D}}$ much larger than the cylinder diameter. Electron collection will in this case be a function of $\left[1+\left(\mathrm{V}_{\mathrm{s}}-\mathrm{V}_{0 \mathrm{~s}}\right) / \mathrm{V}_{\mathrm{e}}\right]^{1 / 2}$ [Laframboise and Sonmor, 1993]. It is understood that end effects at the boom tips and near the spacecraft makes this a 


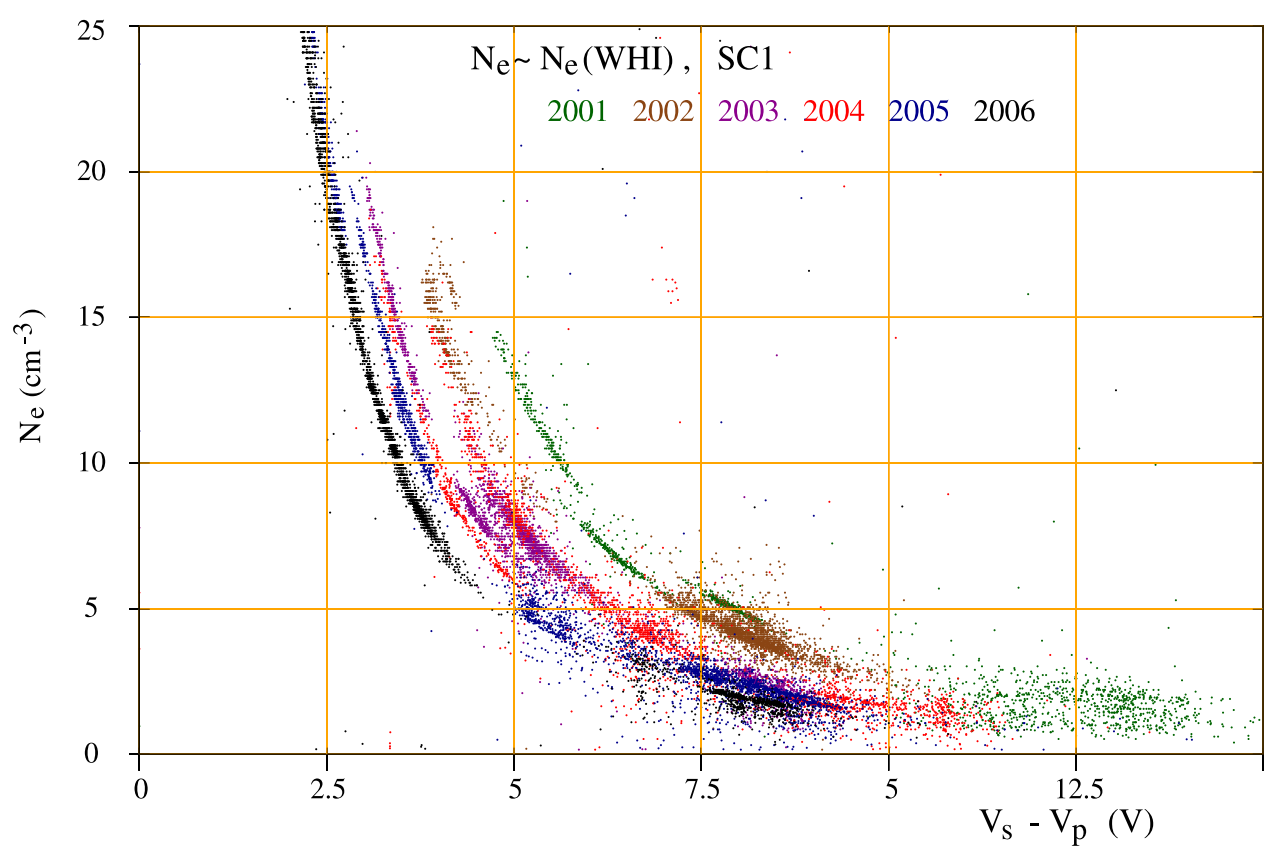

Figure 7. Selected electron densities measured by WHISPER on Cluster SC1 in the solar wind for the months January-April as a function of $\left(V_{s}-V_{p}\right)$ for the years 2001 to 2006.

poor approximation. However, in view of the smaller area of the booms, and the fact that we will consider situations where $\left(\mathrm{V}_{\mathrm{s}}-\mathrm{V}_{0 \mathrm{~s}}\right)$ is comparable to $\mathrm{V}_{\mathrm{e}}$, uncertainties in electron collection of the booms will result in much smaller uncertainties than those of electron density determinations to be described. We therefore can write as an acceptable approximation for $\mathrm{I}_{\mathrm{eS}}$ :

$$
\mathrm{I}_{\mathrm{eS}}=\mathrm{I}_{\mathrm{es} 0}\left[1+\left(\mathrm{V}_{\mathrm{s}}-\mathrm{V}_{0 \mathrm{~s}}\right) / \mathrm{V}_{\mathrm{e}}\right]+\mathrm{I}_{\mathrm{eb} 0}\left[1+\left(\mathrm{V}_{\mathrm{s}}-\mathrm{V}_{0 \mathrm{~s}}\right) / \mathrm{V}_{\mathrm{e}}\right]^{1 / 2}
$$

where $I_{\text {es0 }}$ is the random electron current to the spacecraft body and $\mathrm{I}_{\mathrm{eb} 0}$ is the random electron current to the booms.

[16] Less photoelectrons escape from the spacecraft to the plasma for a satellite in a tenuous plasma with $\left(\mathrm{V}_{\mathrm{s}}-\mathrm{V}_{0 \mathrm{~s}}\right)$ positive and large. However, the probe systems are kept closer to $V_{0 s}$, and $\left(f_{p} I_{p h p}+f_{a} I_{p h a}\right)$ will not be reduced to the same degree, and may for very positive spacecraft potentials be a significant source of photoelectrons to the plasma (see Figure 5 and Appendix B).

\subsection{Calibrations With WHISPER}

[17] Figure 7 is a plot of electron densities measured by WHISPER, $\mathrm{N}_{\mathrm{e}}(\mathrm{WHI})$, as a function of $\left(\mathrm{V}_{\mathrm{s}}-\mathrm{V}_{\mathrm{p}}\right)$ for selected times with stable solar wind conditions in the January-March time frame, every year from 2001 to 2006. The probe bias current, $I_{b}$, was $170 \mathrm{nA}$ for 2001 and $140 \mathrm{nA}$ for the following years. There is a clear shift to smaller $\left(V_{s}-V_{p}\right)$ values from near solar maximum in 2001 to near solar minimum in 2006 . This is very likely caused by reduced solar radiation near solar minimum as reported by Brace et al. [1988]. The shift of the curves to the left from 2001 to 2006 can be understood by the fact that $\left(\mathrm{V}_{\mathrm{s}}-\right.$ $\left.\mathrm{V}_{0 \mathrm{~s}}\right)$ will be reduced more than $\left(\mathrm{V}_{\mathrm{p}}-\mathrm{V}_{\mathrm{np}}\right)$ because the probes, kept closer to the plasma potential by the bias current, will have a steeper current voltage gradient. This results in smaller values of $\left(V_{s}-V_{p}\right)$ in 2006 .
[18] It is clear from Figure 7 that it does not make sense to develop general formulae to get $\mathrm{N}_{\mathrm{e}}$ from measurements of $\left(\mathrm{V}_{\mathrm{s}}-\mathrm{V}_{\mathrm{p}}\right)$ in the solar wind, the magnetosheath and the plasmasphere. When high time resolution measurements of $\mathrm{N}_{\mathrm{e}}$ are required in these regions, the $\mathrm{N}_{\mathrm{e}}$ versus $\left(\mathrm{V}_{\mathrm{s}}-\mathrm{V}_{\mathrm{p}}\right)$ relation must be established for any particular time period. This analytic function can then be used for high time resolution information on $\mathrm{N}_{\mathrm{e}}$ based on $\left(\mathrm{V}_{\mathrm{s}}-\mathrm{V}_{\mathrm{p}}\right)$ measurements with five samples per second. Such information is of particular interest to estimate density gradients and boundary velocities using simultaneous measurements of the four Cluster spacecraft.

[19] WHISPER and EFW solar wind data can be used to find $\mathrm{I}_{\mathrm{phS}}$ up to spacecraft potentials of $+(10-15) \mathrm{V}$ and thereby lead on to the calibration with CIS and PEACE in the plasma sheet. Figure 8 shows $\mathrm{I}_{\mathrm{phS}}$ derived from measurements in the solar wind of $\mathrm{N}_{\mathrm{e}}$ versus $\left(\mathrm{V}_{\mathrm{s}}-\mathrm{V}_{0 \mathrm{~s}}\right)$ performed from January to March 2001. Two examples of the shape of $\mathrm{I}_{\mathrm{eS}}$ for two densities $\left(\mathrm{N}_{\mathrm{e}}=45 \mathrm{~cm}^{-3}\right.$ and $\mathrm{N}_{\mathrm{e}}=$ $4 \mathrm{~cm}^{-3}$ ) with $\mathrm{V}_{\mathrm{e}}$ in each case varying between $10 \mathrm{~V}$ and $20 \mathrm{~V}$ indicate that exact knowledge of the electron energy in the solar wind is not critical for determining $\mathrm{I}_{\mathrm{phS}}$. The spacecraft photoelectron saturation current $\mathrm{I}_{\mathrm{phS} 0} \approx 280 \mu \mathrm{A}$ for early 2001 based on extrapolation of the $\mathrm{I}_{\mathrm{phs}}$ curve in Figure 8 to $\left(\mathrm{V}_{\mathrm{s}}-\mathrm{V}_{0 \mathrm{~s}}\right)=0$. This provides a good starting point when we later will determine $I_{p h s}$ to higher values of $\left(\mathrm{V}_{\mathrm{s}}-\mathrm{V}_{\mathrm{s} 0}\right)$, described in section 3.6. Figure $\mathrm{A} 1$ in Appendix A shows that the probe photoelectron saturation current $\mathrm{I}_{\mathrm{php0}}$ was approximately $330 \mathrm{nA}$ in 2001. For a projected sunlit area of the probe of $50 \mathrm{~cm}^{2}$, this corresponds to a photoelectron current density of $66 \mu \mathrm{Am}^{-2}$. From equation (4) $\left(\mathrm{I}_{\mathrm{phS}}=-\mathrm{I}_{\mathrm{eS}}\right)$ we find that the spacecraft, with a projected area to the Sun of approximately $4 \mathrm{~m}^{2}$, has a similar saturation photoelectron current density of approximately $280 / 4=70 \mu \mathrm{Am}^{-2}$. This agrees with the observation that the spacecraft and the probes, with $\mathrm{I}_{\mathrm{b}}$ set 


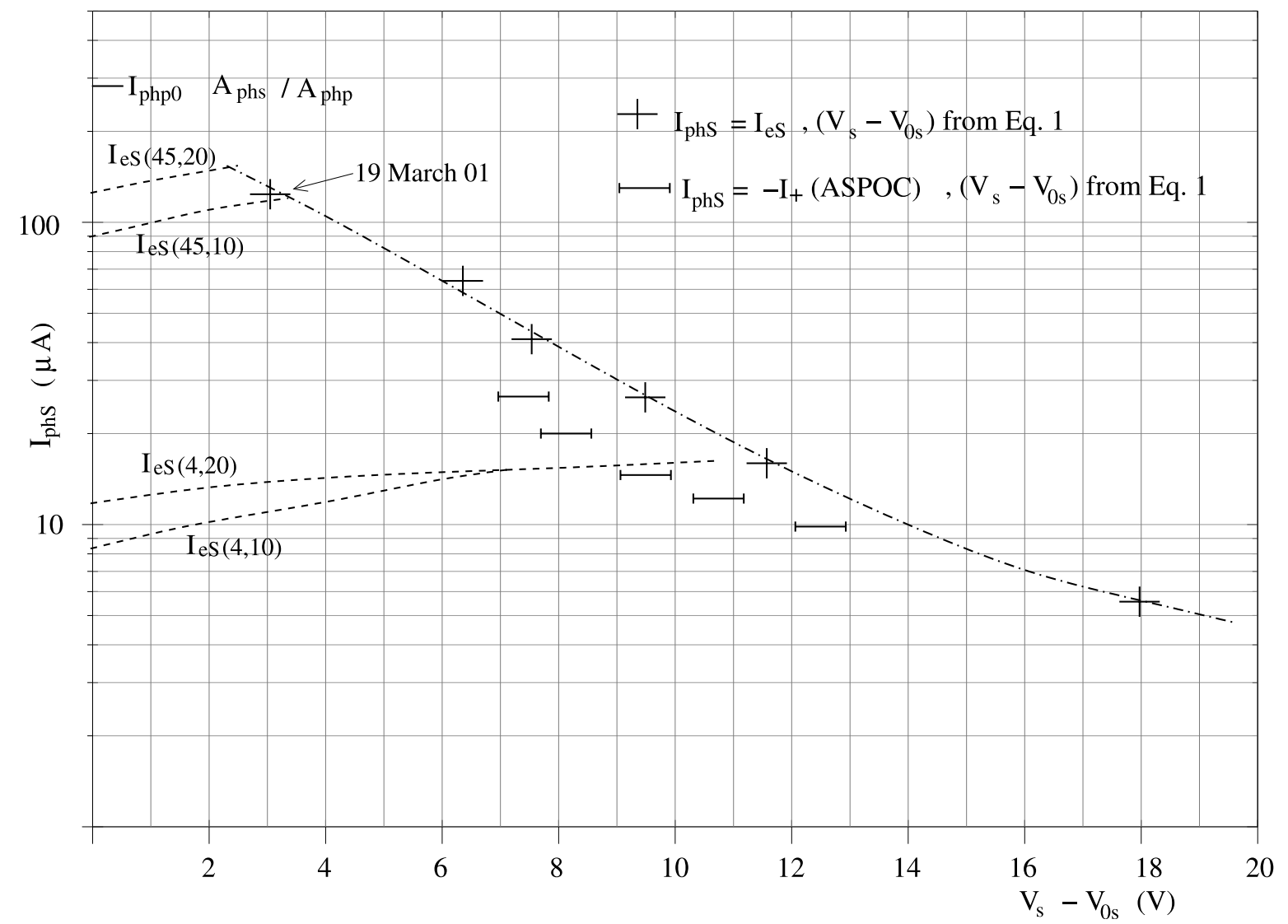

Figure 8. The spacecraft photoelectron characteristic $\left(\mathrm{I}_{\mathrm{phS}}\right)$ as a function of the spacecraft potential $\left(\mathrm{V}_{\mathrm{s}}-\mathrm{V}_{0 \mathrm{~s}}\right)$ in early 2001 based on selected solar wind electron density data from WHISPER and assuming that the mean electron energy is $(10-20) \mathrm{eV}$. Comparison with $\mathrm{I}_{\mathrm{phs}}$ derived from ASPOC ion current stepping in a tenuous plasma, where $\mathrm{I}_{+}(\mathrm{ASPOC})$ is in balance with $\mathrm{I}_{\mathrm{phS}}$, yields information about the electric connection between the outer surfaces on Cluster and the inner structure reference point used for potential measurements.

to zero, come to nearly the same potential in a dense solar wind plasma (Appendix A), and indicates that the spacecraft current collection model for the spacecraft is a fair approximation.

\subsection{Calibration With ASPOC}

[20] The ASPOC experiment emits $\sim 6 \mathrm{keV}$ Indium ions during planned periods in order to bring a very positive spacecraft in a tenuous plasma to a smaller positive potential and thereby support particle experiment performance. $\mathrm{I}_{\mathrm{eS}}$ can in this case be neglected compared to the ASPOC ion current $\left(\mathrm{I}_{+}\right)$, and we expect that in this case $\left|\mathrm{I}_{+}\right|=\left|\mathrm{I}_{\mathrm{phS}}\right|$. Figure 8 shows $\mathrm{I}_{\mathrm{phS}}$ values derived from $\mathrm{I}_{+}$stepped between $10 \mu \mathrm{A}$ and $25 \mu \mathrm{A}$ in a tenuous plasma where one spacecraft with no ASPOC operation was at approximately $+40 \mathrm{~V}$. The $\mathrm{I}_{\mathrm{phS}}$ (ASPOC) versus $\left(\mathrm{V}_{\mathrm{s}}-\mathrm{V}_{0 \mathrm{~s}}\right)$ curve, based on data from December 2000, differs from the $\mathrm{I}_{\mathrm{phs}}$ curve based on WHISPER data in the solar wind in early 2001. The solar cells on Cluster have a coating designed and tested to have sufficient surface conductivity to keep all surfaces within one volt. This is important to avoid that sunlit surfaces with photoelectron emission, and shadowed surfaces, will differ in potential. Bonding strips between many points on the surface and the inner structure at a potential $V_{r}$ form multiple highly conductive paths. However, most of the surface will have a resistance to all bonding strips resulting in a resistance, $R_{S}$, between the outer surfaces at a potential $\mathrm{V}_{\mathrm{s}}$ and $\mathrm{V}_{\mathrm{r}}$. During ASPOC operation $\mathrm{I}_{+}$will generate a potential drop, $I_{+} R_{s}$, directed from $V_{s}$ to $V_{r}$. The measured value of $V_{s}$ is therefore $I_{+} R_{s}$ smaller than the true value of $\mathrm{V}_{\mathrm{s}}$. By comparing the curves of $\mathrm{I}_{\mathrm{phS}}$ (from equation (3)) and $\mathrm{I}_{\mathrm{phS}}$ (ASPOC) it appears that the latter is shifted by a fraction of a volt to smaller $\left(V_{s}-V_{o s}\right)$ values when $I_{+}$is increased from $10 \mu \mathrm{A}$ to $25 \mu \mathrm{A}$. This corresponds to a value of $R_{\mathrm{s}}$ in the range $(10-30) \mathrm{k} \Omega$, in agreement with work by Torkar et al. [2005]. They found that $\mathrm{R}_{\mathrm{s}}$ is approximately $20 \mathrm{k} \Omega$. With this information it is possible to find the true value of $V_{s}$ during ASPOC operations by applying the $\mathrm{I}_{+} \mathrm{R}_{\mathrm{s}}$ correction. The bias current to the four probes will generate a negligible potential drop over $\mathrm{R}_{\mathrm{s}}$ of the order $10^{-3} \mathrm{~V}$. Measurements of $\mathrm{V}_{\mathrm{s}}$ during no ASPOC operation therefore do not require correction thanks to this sufficiently small value of $R_{\mathrm{s}}$.

\subsection{Calibrations With CIS and PEACE in the Plasma Sheet}

[21] Plasma sheet electrons have energies near or above $1 \mathrm{keV}$ and experience a negligible additional acceleration for spacecraft potentials reaching maximum values of $+(30-40) \mathrm{V}$ in the plasma sheet. $\mathrm{I}_{\mathrm{phS}}$, in balance with $\mathrm{I}_{\mathrm{eS}}$, can therefore be determined from equation (5) if we 


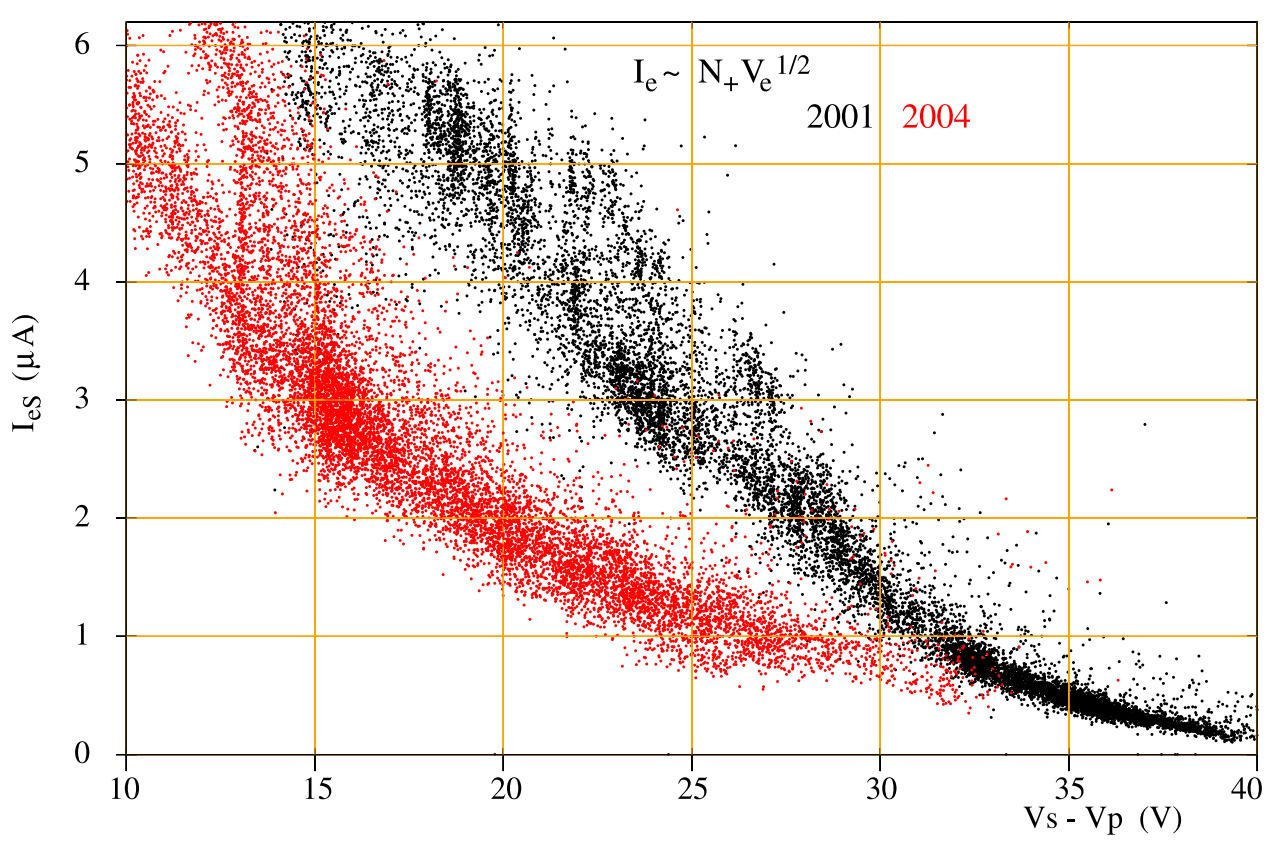

Figure 9. Photoelectron characteristic for the complete spacecraft $\left(\mathrm{I}_{\mathrm{phS}}\right)$ for selected periods in. August-October 2001 and 2004 as a function of $\left(\mathrm{V}_{\mathrm{s}}-\mathrm{V}_{\mathrm{p}}\right)$ based on measurements of $\mathrm{N}_{+}$(CIS) and mean electron energy $\mathrm{eV}_{\mathrm{e}}(\mathrm{PEACE})$ in the plasma sheet. Note that $\mathrm{I}_{\mathrm{phS}}=-\mathrm{I}_{\mathrm{eS}}$ (see equation (4)).

know $\mathrm{N}_{\mathrm{e}}$ and $\mathrm{V}_{\mathrm{e}}$ and $\left(\mathrm{V}_{0}-\mathrm{V}_{0 \mathrm{~s}}\right)$. We have chosen to use $\mathrm{N}_{+}(\mathrm{CIS})=\mathrm{N}_{\mathrm{e}}$ and $\mathrm{V}_{\mathrm{e}}(\mathrm{PEACE})$ for determination of $\mathrm{I}_{\mathrm{eS}}=$ $-\mathrm{I}_{\mathrm{phs}}$. Figure 9 shows $\mathrm{I}_{\mathrm{eS}} \sim\left|\mathrm{N}_{+} \mathrm{V}_{\mathrm{e}}\right|$ as a function of $\left(\mathrm{V}_{\mathrm{s}}-\mathrm{V}_{\mathrm{p}}\right)$ for selected periods in August-October 2001 and 2004 and demonstrates that there is a marked reduction of $\mathrm{I}_{\mathrm{phS}}$ from near solar maximum toward solar minimum. This reduction is more pronounced than that of the Lyman alpha radiation reported by Brace et al. [1988]. $\mathrm{I}_{\mathrm{phS}}$ in the plasma sheet is determined by EUV radiation and soft $\mathrm{X}$ rays which are strongly reduced toward solar minimum. Radiation from this part of the solar spectrum is necessary for production of photoelectrons of high enough energy to escape to the plasma from the positive spacecraft in the plasma sheet. There are increases of $\mathrm{I}_{\mathrm{phs}}$ above the average values for some periods with high solar activity. This makes it necessary to be aware that, in addition to the yearly variations, possible variations are present due to solar activity on day or shorter timescales.

\subsection{Calibrations With EDI}

[22] The EDI experiment normally operates with electron currents from two guns, each emitting $40 \mathrm{nA}$ of $1-2 \mathrm{keV}$ electrons. This has negligible influence on the spacecraft potential in practically all regions of the Cluster orbit. In some planned periods the gun current per gun $\left(\mathrm{I}_{\mathrm{EDI}}\right)$ is increased to levels up to $300 \mathrm{nA}$. The spacecraft will then be driven more positive resulting in a reduction of $\mathrm{I}_{\mathrm{phS}}$ and an increase of $\mathrm{I}_{\mathrm{eS}}$. This can be used to get information about $\mathrm{I}_{\mathrm{phS}}$ at very large spacecraft potentials. It is not possible to look for EDI high current on/off because the EDI electron current is changed gradually. However, EDI is not operating on SC4 and has been used as a reference for the other spacecraft operated with a high $\mathrm{I}_{\mathrm{EDI}}$. An opportunity to get good measurements occurred in the autumn of 2003 when the Cluster tetrahedron was small and all spacecraft were in very similar plasma conditions in the lobe and plasma sheet boundary layer. Repeated observations showed that when $\left(\mathrm{V}_{\mathrm{s}}-\mathrm{V}_{\mathrm{p}}\right)$ was close to $40 \mathrm{~V}$ on $\mathrm{SC} 4$, other spacecraft with high $\mathrm{I}_{\mathrm{EDI}}$ experienced spacecraft to probe potential differences equal to or greater than $70 \mathrm{~V}$. This corresponds to $\left(\mathrm{V}_{\mathrm{s}}-\mathrm{V}_{\mathrm{s} 0}\right)$ reaching values above $80 \mathrm{~V}$.

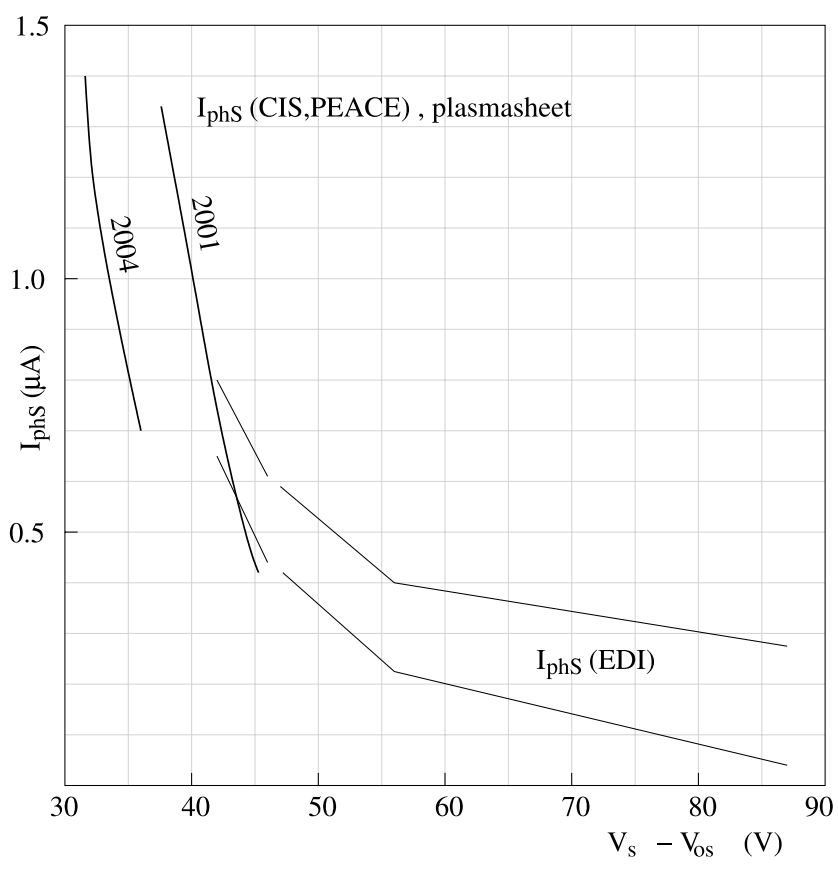

Figure 10. Calculation of $\mathrm{I}_{\mathrm{phS}}$ limits between $\left(\mathrm{V}_{\mathrm{s}}-\mathrm{V}_{0 \mathrm{~s}}\right)=$ $42 \mathrm{~V}$ and $87 \mathrm{~V}$ based on EDI high electron current $(250 \mathrm{nA})$ operation on SC3 and no EDI operation on SC4 18. July 2003, 2100-2200 UT. The small separation between spacecraft in 2003 made it possible to use differences in potential for SC3 and SC4 to find these limits of $\mathrm{I}_{\mathrm{phS}}$. 


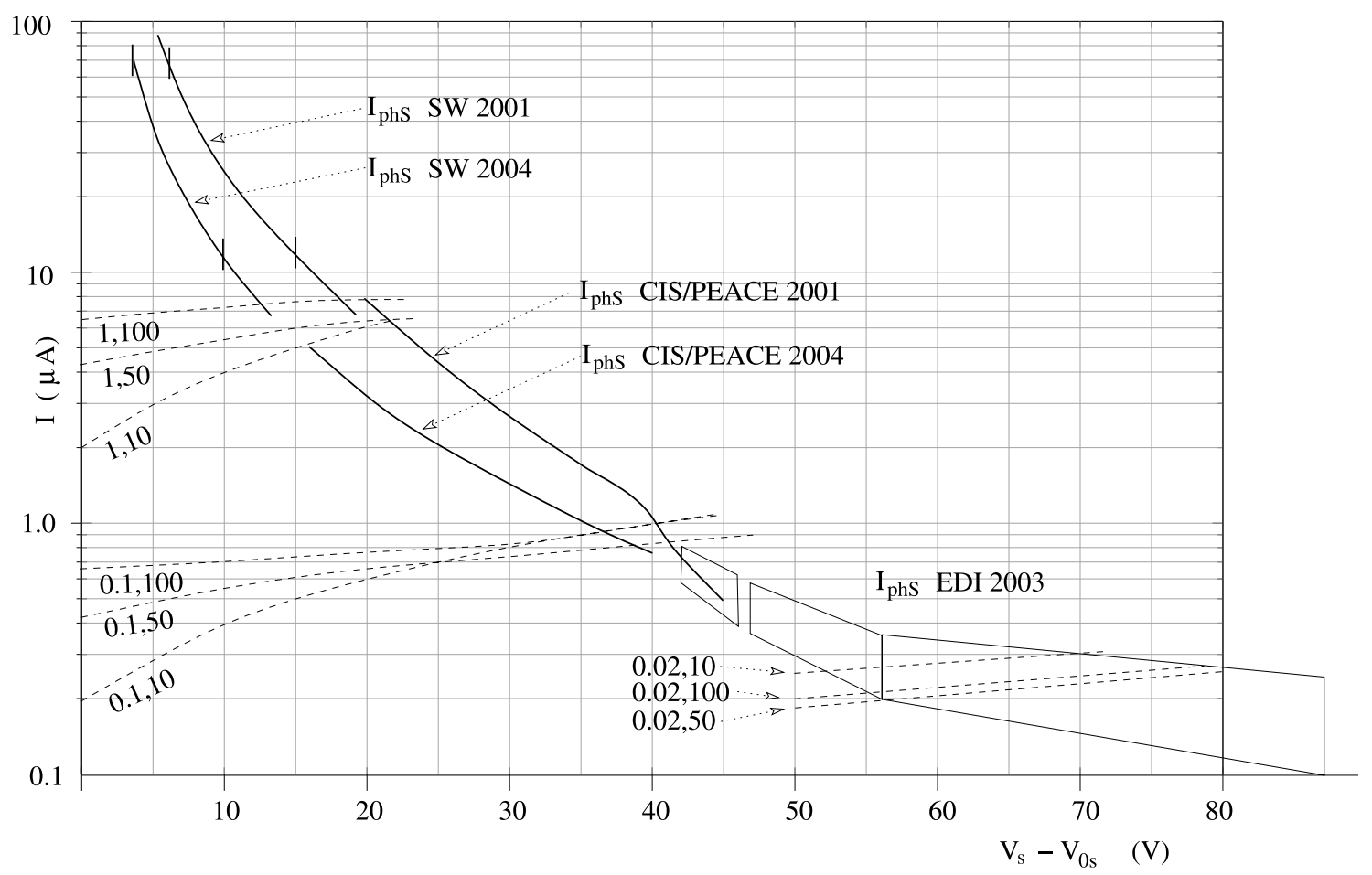

Figure 11. $\mathrm{I}_{\mathrm{phS}}$ as a function of $\left(\mathrm{V}_{\mathrm{s}}-\mathrm{V}_{0 \mathrm{~s}}\right)$ for quiet to moderately active solar conditions in August-October 2001 and 2004. Examples of the current balance between $\mathrm{I}_{\mathrm{phS}}$ and $\mathrm{I}_{\mathrm{eS}}$ are given for different plasmas marked as $\left(\mathrm{N}_{\mathrm{e}}\right.$ in $\left.\mathrm{cm}^{-1}, \mathrm{~V}_{\mathrm{e}}\right)$.

[23] Three different time periods with tenuous plasma in the lobes were selected when $\left(\mathrm{V}_{\mathrm{s}}-\mathrm{V}_{0 \mathrm{~s}}\right)$ of $\mathrm{SC} 4$ with $\mathrm{I}_{\mathrm{EDI}}=0$ had values of respectively $42 \mathrm{~V}, 47 \mathrm{~V}$ and $56 \mathrm{~V}$. $\mathrm{SC} 3$, operated with $\mathrm{I}_{\mathrm{EDI}}=0.25 \mu \mathrm{A}$ in the same time periods, observed $\left(\mathrm{V}_{\mathrm{s}}-\mathrm{V}_{0 \mathrm{~s}}\right)$ values of $46 \mathrm{~V}, 56 \mathrm{~V}$, and $87 \mathrm{~V}$. The current balance on SC4 is $\mathrm{I}_{\mathrm{phS}}=-\mathrm{I}_{\mathrm{eS}}$ and the current balance on SC3 is $\mathrm{I}_{\mathrm{phS}}+\mathrm{I}_{\mathrm{EDI}}=-\mathrm{I}_{\mathrm{eS}}$. This makes it possible to find limits for $\mathrm{I}_{\mathrm{phS}}$ as a function of $\left(\mathrm{V}_{\mathrm{s}}-\mathrm{V}_{\mathrm{os}}\right)$ in the (42-87) V range. Figure 10 shows calculations of $\mathrm{I}_{\mathrm{phS}}$ for two different starting values for $\mathrm{I}_{\mathrm{phS}}$ on SC4 at $42 \mathrm{~V}$. $\mathrm{I}_{\mathrm{eS}}$ increase over the (42-87) $\mathrm{V}$ depends on $\mathrm{V}_{\mathrm{e}}$ and a value $\mathrm{V}_{\mathrm{e}}=50 \mathrm{~V}$, which is close to the expected value in a very tenuous lobe plasma (see Figure 16), has been chosen for these calculations. The lower limits of $\mathrm{I}_{\mathrm{phS}}$ near $40 \mathrm{~V}$, from CIS/PEACE measurements in the plasma sheet, are traced in Figure 10. The upper $\mathrm{I}_{\mathrm{phs}}$ curve, based on EDI operation, is an approximate continuation of the plasma sheet data. A starting value of $\mathrm{I}_{\mathrm{phS}}$ at $\left(\mathrm{V}_{\mathrm{s}}-\mathrm{V}_{0 \mathrm{~s}}\right)=$

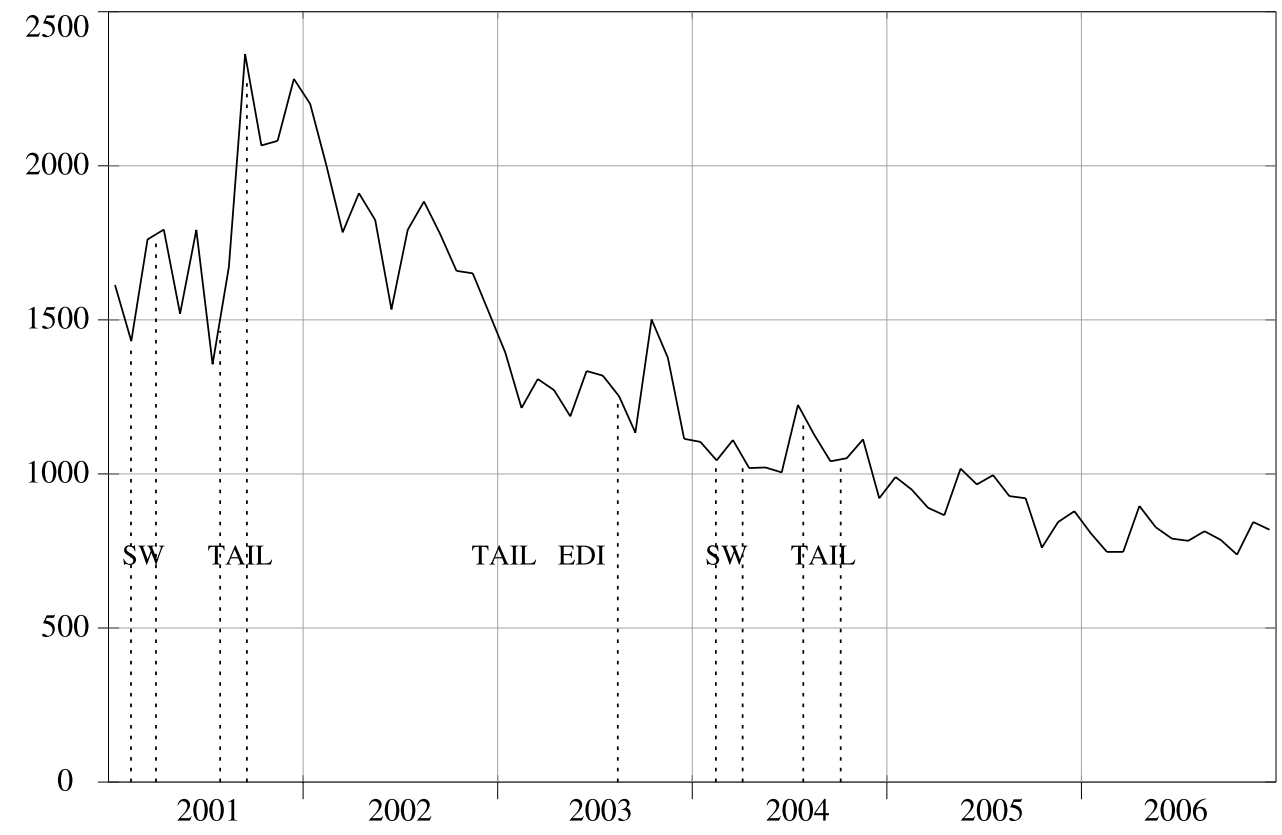

Figure 12. Monthly values of the $10.7 \mathrm{~cm}$ solar radiation for the years 2001-2006. 


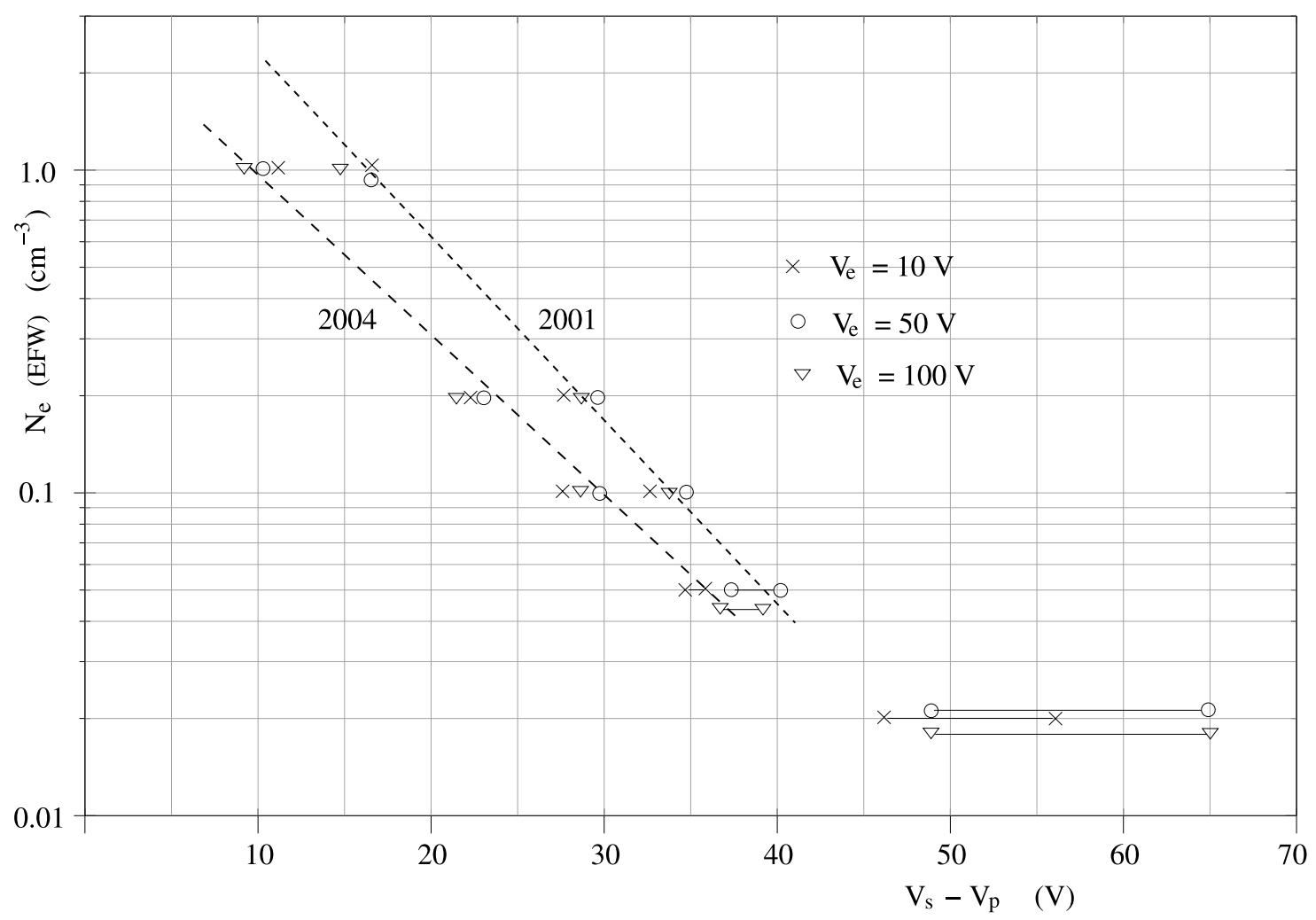

Figure 13. Electron densities as a function of $\left(V_{s}-V_{p}\right)$ for 2001 and 2004 for electrons in the energy range $(10-100) \mathrm{eV}$.

$42 \mathrm{~V}$ below the lowest of the two calculated curves will result in $I_{p h S}$ coming to zero for $\left(V_{s}-V_{0 s}\right)$ less than $87 \mathrm{~V}$, which is in contradiction with observations. On the basis of EDI operation, and assuming $\mathrm{V}_{\mathrm{e}}=50 \mathrm{~V}, \mathrm{I}_{\mathrm{phS}}$ is therefore estimated to be between the two curves in Figure 10.

\subsection{Photoelectron Characteristic, $I_{p h s}$, for Spacecraft Potentials up to $\sim 80 \mathrm{~V}$ and Its Variation With Solar Radiation}

[24] Minimum values of $\mathrm{I}_{\mathrm{phS}}$ for 2001 and 2004, based on calibrations in the solar wind, the plasma sheet and for EDI operations in a lobe plasma, are presented in Figure 11. The values based on EFW and WHISPER in the solar wind serve the purpose of leading on to $\mathrm{I}_{\mathrm{phS}}$ at higher potentials. Using the EFW-CIS-PEACE calibration in the plasma sheet, the minimum $\mathrm{I}_{\mathrm{phS}}$ values are traced for 2001 and 2004. $\mathrm{I}_{\mathrm{phS}}$ may increase above these traces for days with high EUV radiation. The EFW-EDI calibration gives the limits of $\mathrm{I}_{\mathrm{phS}}$ for spacecraft potentials between $+42 \mathrm{~V}$ and $+87 \mathrm{~V}$ for a favorable calibration situation in 2003. Lacking continuous EUV and X-ray radiation levels we use the $10.7 \mathrm{~cm}$ solar radiation as an indicator of solar activity. Figure 12 shows the monthly average of the $10.7 \mathrm{~cm}$ radiation for all calibration periods and also shows that that the solar radiation level for the EFW-EDI calibration in 2003 was not much higher than that for 2004.

\section{Electron Density as a Function of $\left(V_{s}-V_{p}\right)$ in the Polar Caps and Lobes (2001-2004)}

[25] We assume that plasma over the polar caps and in the lobes will have electrons in the $(10-100) \mathrm{eV}$ energy range.
Furthermore we will use equation (5) to find $I_{e S}$ as a function of $\left(\mathrm{V}_{\mathrm{s}}-\mathrm{V}_{0 \mathrm{~s}}\right)$ for typical polar cap and lobe densities and the following mean electron energies: $10 \mathrm{eV}$, $50 \mathrm{eV}$, and $100 \mathrm{eV}$. Some examples of $\mathrm{I}_{\mathrm{eS}}$ curves and their crossing of the $\mathrm{I}_{\mathrm{phS}}$ curves for 2001 and 2004 are given in Figure 11. These crossings can be used to find $\mathrm{N}_{\mathrm{e}}$ as a function of $\left(\mathrm{V}_{\mathrm{s}}-\mathrm{V}_{0 \mathrm{~s}}\right)$. With knowledge of the $\left(\mathrm{V}_{\mathrm{p}}-\mathrm{V}_{\mathrm{np}}\right)$, being $(2.2 \pm 0.2) \mathrm{V}$ in 2001 and $(0.9 \pm 0.2) \mathrm{V}$ in 2004 , and using equation (1), $\mathrm{N}_{\mathrm{e}}(\mathrm{EFW})$ as a function of the measured parameter $\left(\mathrm{V}_{\mathrm{s}}-\mathrm{V}_{\mathrm{p}}\right)$ can be established. The result is presented in Figure 13. There are relatively small differences in the crossings of $\mathrm{I}_{\mathrm{eS}}$ and $\mathrm{I}_{\mathrm{phS}}$ for different electron energies in the range $10-100 \mathrm{eV}$. The following equations give approximate values of $\mathrm{N}_{\mathrm{e}}$ assuming that the electron energy is in this range. The equations should be used for $\left(\mathrm{V}_{\mathrm{s}}-\mathrm{V}_{\mathrm{p}}\right)$ above approximately $10 \mathrm{~V}$.

$$
\begin{aligned}
2001: \mathrm{N}_{\mathrm{e}}(\text { EFW })= & 10 \exp -\left[\left(\mathrm{V}_{\mathrm{s}}-\mathrm{V}_{\mathrm{p}}\right) / 7.4 \mathrm{~V}\right] \\
& \left.+0.05 \exp -\left[\left(\mathrm{V}_{\mathrm{s}}-\mathrm{V}_{\mathrm{p}}\right) / 30 \mathrm{~V}\right]\right\} \mathrm{cm}^{-3} \\
2004: \mathrm{N}_{\mathrm{e}}(\mathrm{EFW})=\left\{3 \exp -\left[\left(\mathrm{V}_{\mathrm{s}}-\mathrm{V}_{\mathrm{p}}\right) / 8.8 \mathrm{~V}\right]\right. & \\
& \left.+0.05 \exp -\left[\left(\mathrm{V}_{\mathrm{s}}-\mathrm{V}_{\mathrm{p}}\right) / 30 \mathrm{~V}\right]\right\} \mathrm{cm}^{-3}
\end{aligned}
$$

The above determination of $\mathrm{N}_{\mathrm{e}}$ probably have error bars of $\pm(10-20) \%$, mostly due to the imprecise knowledge of solar radiation. For $\left(\mathrm{V}_{\mathrm{s}}-\mathrm{V}_{\mathrm{p}}\right)$ above $40 \mathrm{~V}$, only the order of magnitude of $\mathrm{N}_{\mathrm{e}}$ can be determined. Therefore it must be permitted to make preliminary relations like the ones above 

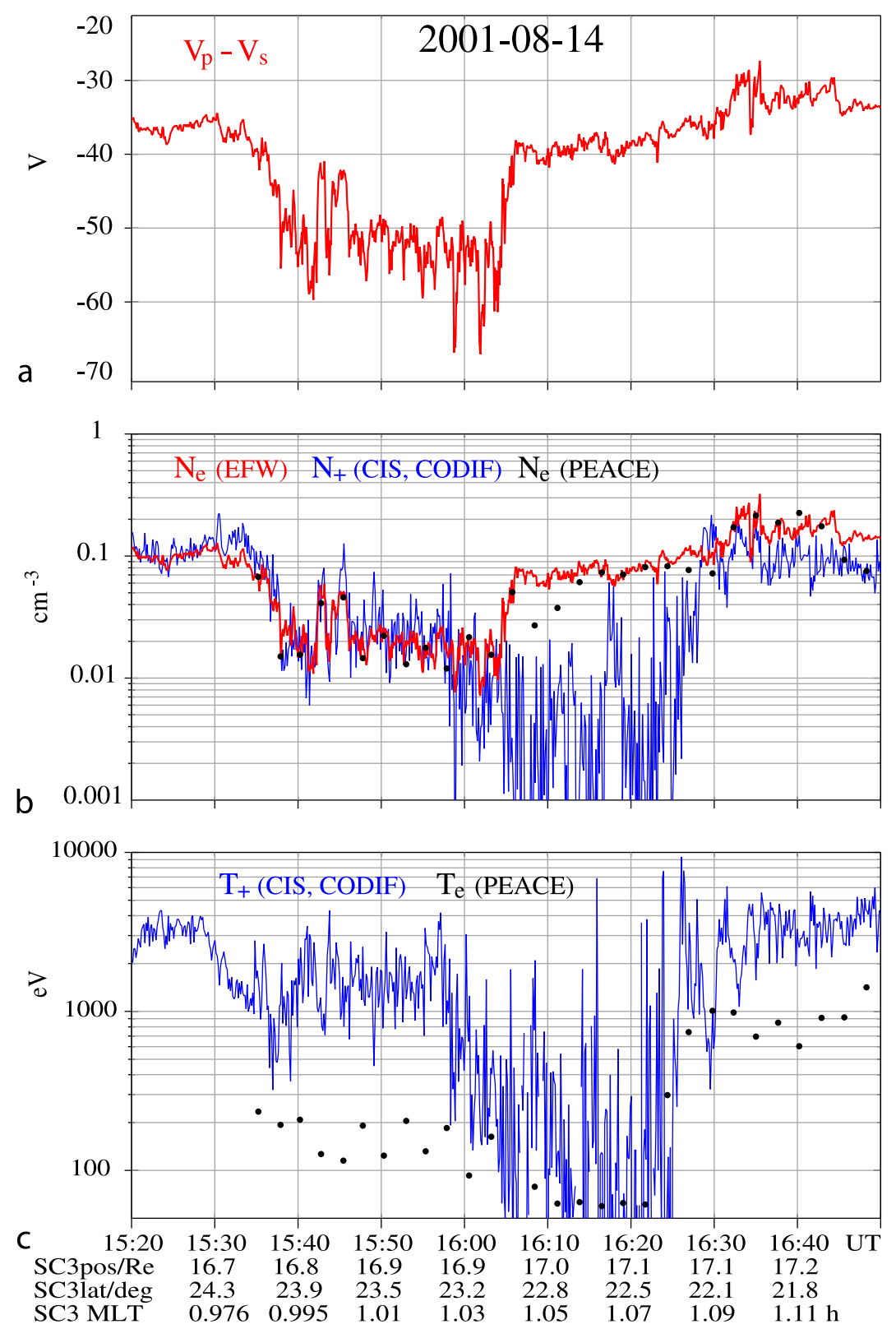

Figure 14. Measurements in the plasma sheet and plasma sheet boundary layer. (a) The probe-spacecraft potential difference $\left(\mathrm{V}_{\mathrm{p}}-\mathrm{V}_{\mathrm{s}}\right)$; (b) $\mathrm{N}_{\mathrm{e}}(\mathrm{EFW}), \mathrm{N}_{+}(\mathrm{CIS})$ and $\mathrm{N}_{\mathrm{e}}$ (PEACE) from moment calculations presented as black dots; (c) $\mathrm{T}_{+}$(CIS) from prime parameters and $\mathrm{T}_{\mathrm{e}}$ (PEACE) from moment calculations.

for 2002 and 2003 by rough assessments of the solar EUV and X-ray levels from the $10.7 \mathrm{~cm}$ radiation and make the interpolation for these years:

$$
\begin{aligned}
2002: \mathrm{N}_{\mathrm{e}}(\mathrm{EFW})= & \left\{6 \exp -\left[\left(\mathrm{V}_{\mathrm{s}}-\mathrm{V}_{\mathrm{p}}\right) / 8.17 \mathrm{~V}\right]\right. \\
& \left.+0.05 \exp -\left[\left(\mathrm{V}_{\mathrm{s}}-\mathrm{V}_{\mathrm{p}}\right) / 30 \mathrm{~V}\right]\right\} \mathrm{cm}^{-3} \\
2003: \mathrm{N}_{\mathrm{e}}(\mathrm{EFW})= & \left\{4 \exp -\left[\left(\mathrm{V}_{\mathrm{s}}-\mathrm{V}_{\mathrm{p}}\right) / 8.6 \mathrm{~V}\right]\right. \\
& \left.+0.05 \exp -\left[\left(\mathrm{V}_{\mathrm{s}}-\mathrm{V}_{\mathrm{p}}\right) / 30 \mathrm{~V}\right]\right\} \mathrm{cm}^{-3}
\end{aligned}
$$

It is important to emphasize that the above equations are approximations of the $\mathrm{N}_{\mathrm{e}}(\mathrm{EFW})$ values and are valid for low solar EUV and X-ray radiation. Figure 9 shows the variations of $\mathrm{I}_{\mathrm{phs}}$, that will occur from day to day and also on smaller timescales. High values of $\mathrm{I}_{\mathrm{phS}}$ can result in $\mathrm{N}_{\mathrm{e}}(\mathrm{EFW})$ being underestimated by 50 to $100 \%$.

\section{Examples of the Use of the Spacecraft Potential Technique}

[26] It has become customary to plot the negative of the spacecraft to probe potential difference, $\left(\mathrm{V}_{\mathrm{p}}-\mathrm{V}_{\mathrm{s}}\right)$, for presentations and publications. This is because an increase in electron density results in an upwards trend in $\left(V_{p}-V_{s}\right)$. In descriptions and discussions to follow this way of presenting the spacecraft potential will be used. 

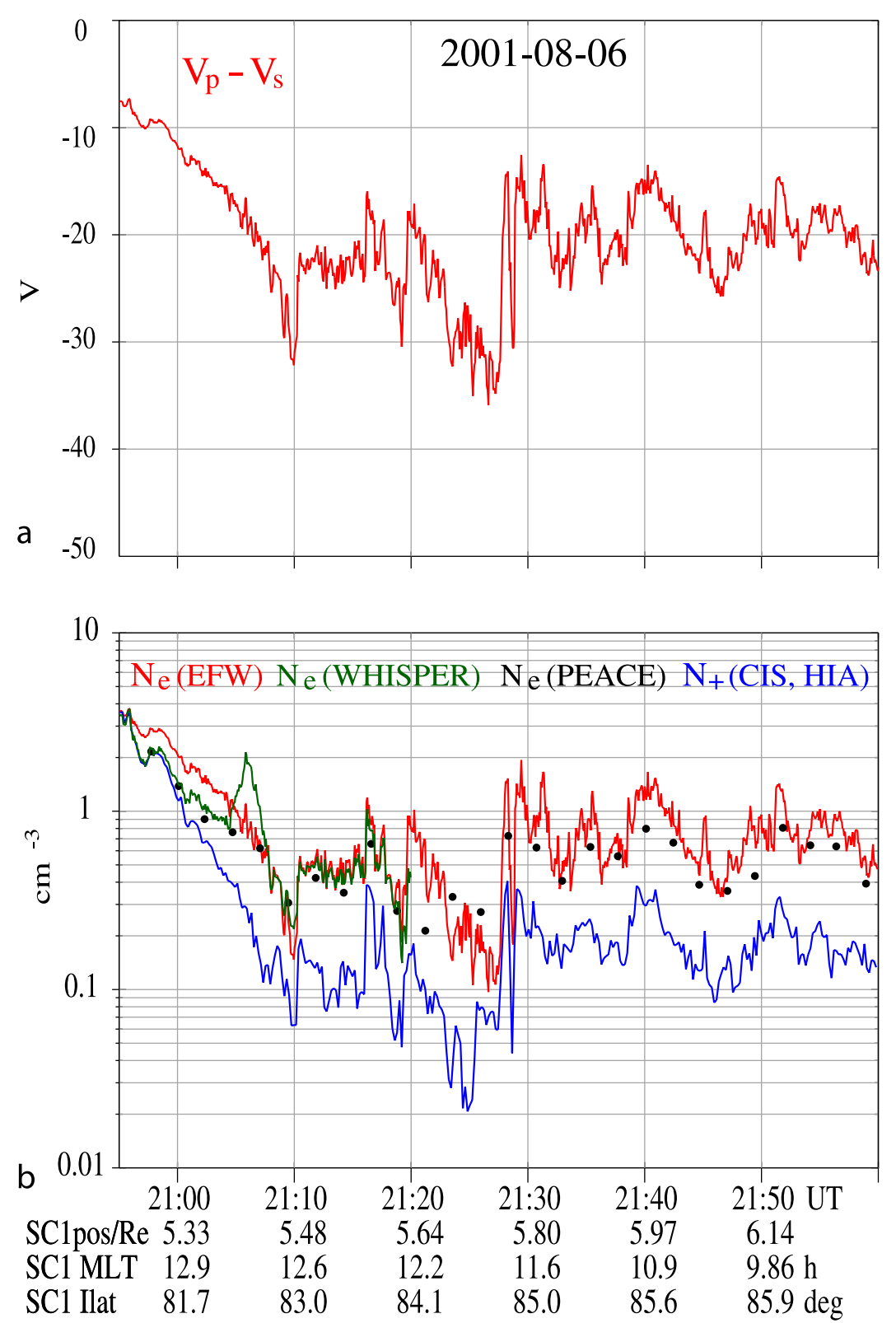

Figure 15. (a) The probe-spacecraft potential difference $\left(\mathrm{V}_{\mathrm{p}}-\mathrm{V}_{\mathrm{s}}\right)$. (b) $\mathrm{N}_{\mathrm{e}}(\mathrm{EFW})$ (red) and $\mathrm{N}_{\mathrm{e}}(\mathrm{WHI})$ (green) are in good agreement for the passage from the polar cap to the northern lobe in the interval 2107 UT to 2120 UT. After this time WHISPER does not yield data; density and related plasma frequency is below the low cut-off frequency of WHISPER. $\mathrm{N}_{\mathrm{e}}$ (PEACE) from moment calculations (black dots) is in good agreement with $\mathrm{N}_{\mathrm{e}}(\mathrm{EFW})$. $\mathrm{N}_{+}(\mathrm{CIS}, \mathrm{HIA})$ (blue) is lower than $\mathrm{N}_{\mathrm{e}}(\mathrm{EFW})$ and $\mathrm{N}_{\mathrm{e}}(\mathrm{WHI})$.

\subsection{Lobe-Boundary Layer-Plasma Sheet Transition in 2001}

[27] Figure 14 shows a compression followed by an expansion of the northern plasma sheet boundary. It was observed on all four Cluster spacecraft but was more pronounced on $\mathrm{SC} 3$ which was closest to the neutral sheet. SC3 was in a very tenuous plasma between $\sim 1538$ UT and $\sim 1604$ UT. The electron and ion temperatures in Figure 14c indicate a plasma sheet population with lower than average energies. Figure $14 \mathrm{~b}$ shows that $\mathrm{N}_{\mathrm{e}}(\mathrm{EFW}), \mathrm{N}_{+}(\mathrm{CIS})$, and $\mathrm{N}_{\mathrm{e}}($ PEACE) are in good agreement. It also demonstrates that $\mathrm{N}_{\mathrm{e}}(\mathrm{EFW})$, using equation (6), also holds for electron energies slightly above $100 \mathrm{eV}$. At $\sim 1604$ UT SC3 entered a plasma with electron and ion energies below $100 \mathrm{eV}$, and the measured ion densities were too low due to rejection of low energy ions. $\mathrm{N}_{\mathrm{e}}(\mathrm{PEACE})$ is in agreement with $\mathrm{N}_{\mathrm{e}}(\mathrm{EFW})$ for part of this interval. SC3 entered the plasma sheet at $\sim 1625 \mathrm{UT}^{\mathrm{N}} \mathrm{N}_{+}$(CIS) is the best reference after $1625 \mathrm{UT}$, and as expected $\mathrm{N}_{\mathrm{e}}(\mathrm{EFW})$ is overestimated when electron energies are close to $1 \mathrm{keV}$.

[28] An $\mathbf{E} \times \mathbf{B}$ velocity of the order $100 \mathrm{~km}^{-1}$ toward the plasma sheet was observed in the 1604-1625 UT interval. Studies of electric fields observed in this interval will not be pursued in this paper, but they deserve detailed studies in the future. The question of ion ram current influence on the spacecraft current balance must be clarified. A rough 

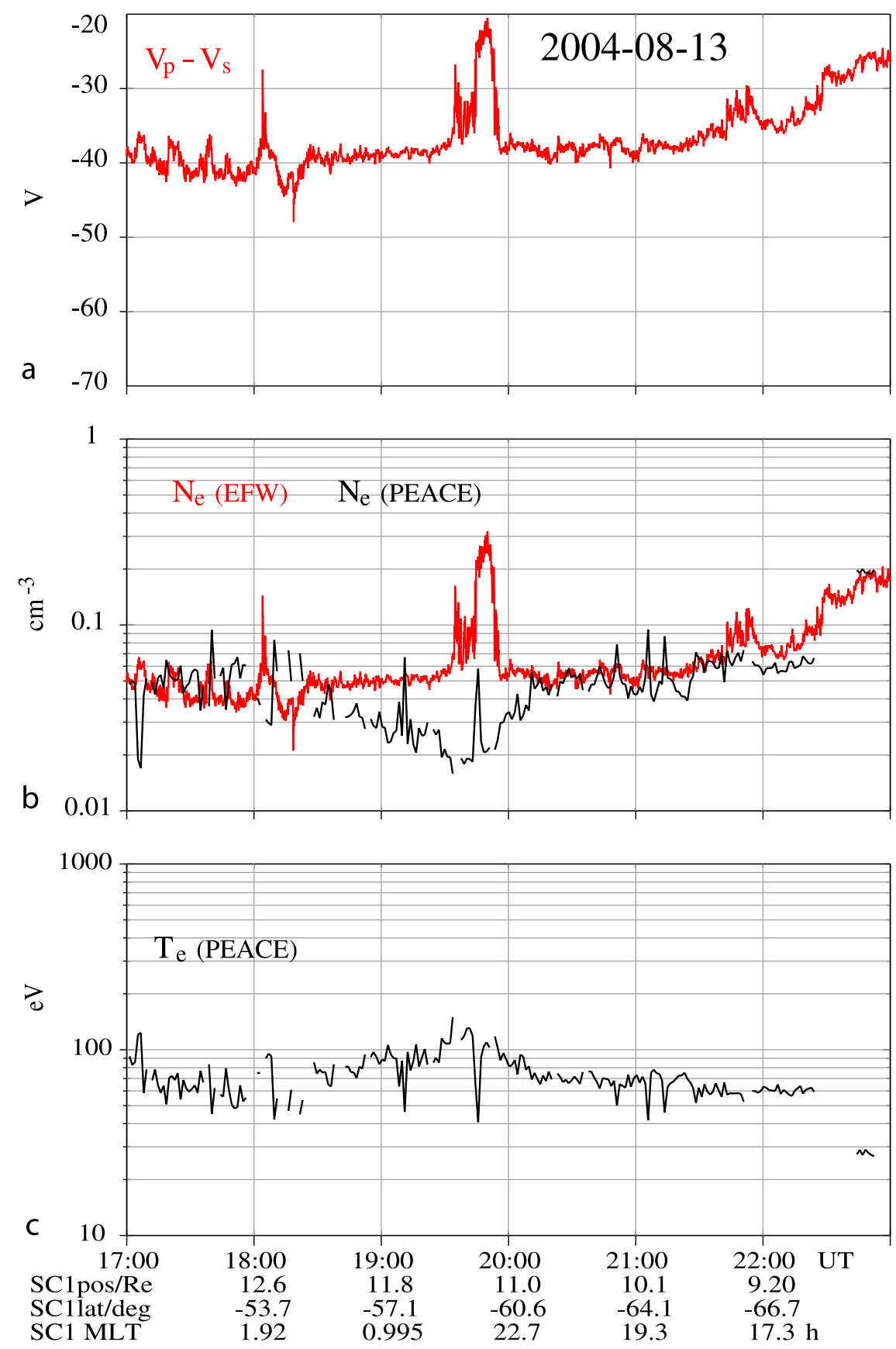

Figure 16. Measurements in the outer lobe. (a) The probe-spacecraft potential difference $\left(\mathrm{V}_{\mathrm{p}}-\mathrm{V}_{\mathrm{s}}\right)$; (b) $\mathrm{N}_{\mathrm{e}}(\mathrm{EFW})$ and $\mathrm{N}_{\mathrm{e}}$ (PEACE) from prime parameters; (c) $\mathrm{T}_{\mathrm{e}}$ (PEACE) from prime parameters.

estimate of the ion ram current can be made if we assume that the Cluster spacecraft has an approximate ion ram area of $10 \mathrm{~m}^{2}$. The ratio between ion and electron currents to the spacecraft for $\mathrm{V}_{\mathrm{e}}=100 \mathrm{~V}$ (Figure 14), and an ion ram velocity of $100 \mathrm{~km} \mathrm{~s}^{-1}$, is $\sim 2 \%$. For higher ion ram velocities, the contribution of ram ions to the spacecraft current balance will increase and must be judged on the background of the rather large uncertainty in the determination of $\mathrm{N}_{\mathrm{e}}(\mathrm{EFW})$.

\subsection{A Cusp-Northern Polar Cap Passage in 2001}

[29] On 6 August 2001 Cluster passed from the poleward edge of the northern cusp into the polar cap. Figure 15a presents $\left(\mathrm{V}_{\mathrm{p}}-\mathrm{V}_{\mathrm{s}}\right)$ of $\mathrm{SC} 1$ for this passage. PEACE measured mean electron energies between $30 \mathrm{eV}$ and $50 \mathrm{eV}$ for the whole passage. $\mathrm{N}_{\mathrm{e}}$ (WHI) provides the best possible reference up to $2120 \mathrm{UT}$, and the agreement between $\mathrm{N}_{\mathrm{e}}(\mathrm{WHI}), \mathrm{N}_{\mathrm{e}}(\mathrm{EFW})$ and $\mathrm{N}_{\mathrm{e}}$ (PEACE), in Figure $15 \mathrm{~b}$, is near to perfect in the interval 2108-2120 UT. At the start of data in Figure 15, $\mathrm{N}_{+}(\mathrm{CIS}), \mathrm{N}_{\mathrm{e}}(\mathrm{WHI})$, and $\mathrm{N}_{\mathrm{e}}(\mathrm{PEACE})$ are in perfect agreement whereas $\mathrm{N}_{\mathrm{e}}(\mathrm{EFW})$ shows an overestimate which indicates that the spacecraft potential technique, as presented in this paper, has limitations for spacecraft potentials below $(10-15) \mathrm{V}$. For more negative values of $\left(\mathrm{V}_{\mathrm{p}}-\mathrm{V}_{\mathrm{s}}\right)$ after $\sim 2100 \mathrm{UT}, \mathrm{N}_{+}(\mathrm{CIS})$ from the HIA 

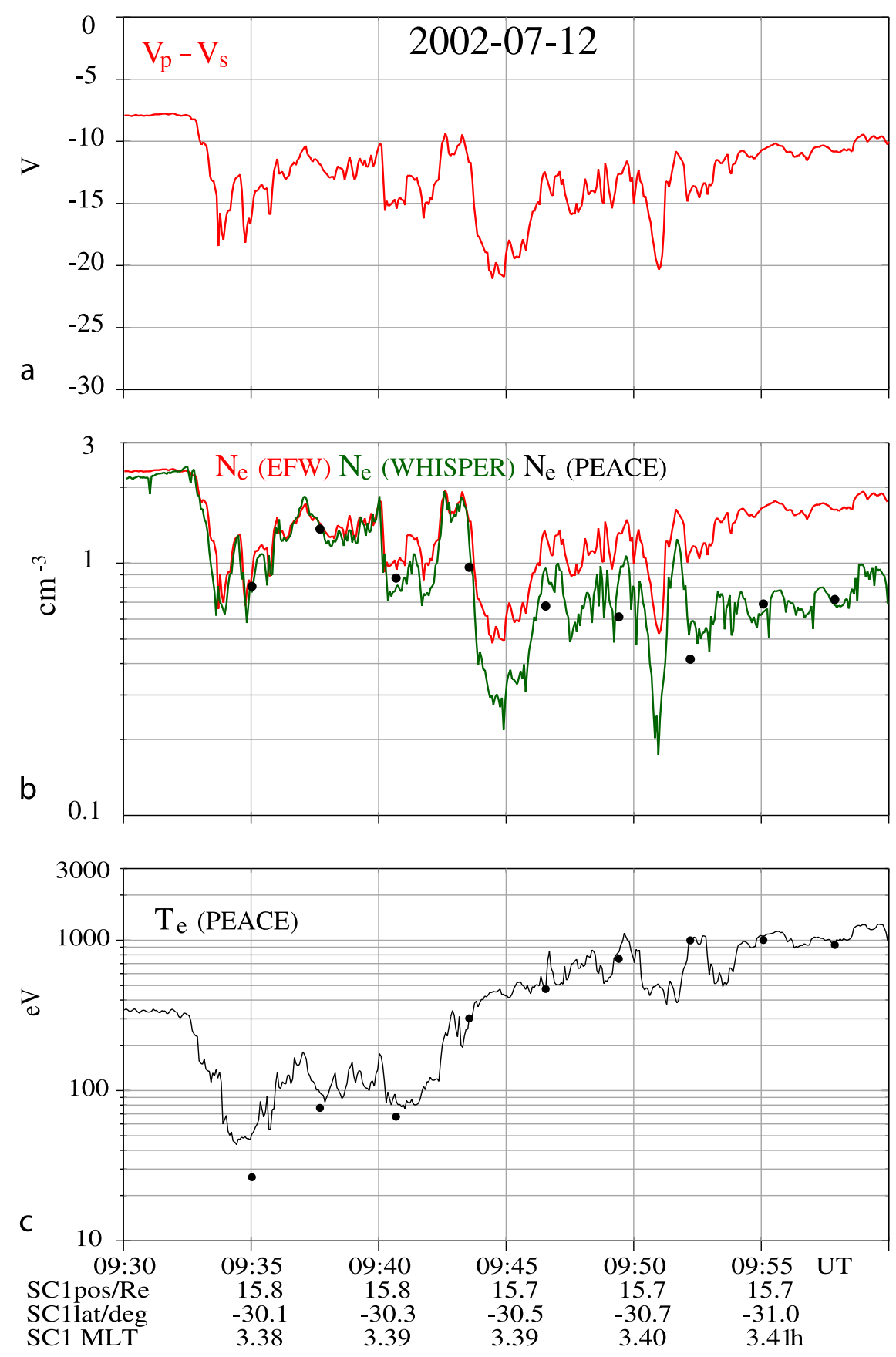

Figure 17. (a) Spacecraft to probe potential measured on Cluster 1 by EFW from 0930 UT to 1000 UT on 12 July 2002. (b) Solid red line shows electron density derived from the probe to spacecraft potential displayed in the top panel using equation (8); solid green line shows electron densities derived from WHISPER soundings; black dots show electron density moments estimated by PEACE. (c) Solid black line shows electron temperature estimated by PEACE (prime parameters), and black dots show PEACE temperatures from moment calculations.

instrument, presented in Figure 15b, is a factor $2-3$ below the densities obtained by EFW and PEACE.

\subsection{A Southern Lobe Passage Far From the Neutral Sheet in 2004}

[30] Figure 16 shows data from EFW and PEACE on SC1 from 13 August 2004 when Cluster was at high latitudes in the southern lobe. Figure 16a shows a decrease of the spacecraft potential near $1950 \mathrm{UT}$, translated into an electron density increase from $0.05 \mathrm{~cm}^{-3}$ to $0.3 \mathrm{~cm}^{-3}$. $\mathrm{T}_{\mathrm{e}}(\mathrm{PEACE})$ is $\sim 60 \mathrm{eV}$ before and $\sim 70 \mathrm{eV}$ after the density increase. $T_{\mathrm{e}}$ (PEACE) increase to just above $100 \mathrm{eV}$ near the density increase. $\mathrm{N}_{\mathrm{e}}$ (PEACE) is in agreement with $\mathrm{N}_{\mathrm{e}}$ (EFW) before and after the density increase. However, $\mathrm{N}_{\mathrm{e}}$ (PEACE) does not follow the $\mathrm{Ne}(\mathrm{EFW})$ maximum. This indicates that the main part of the electrons probably had 
low energy and therefore difficult to separate from emitted photoelectrons attracted back to the spacecraft. CIS ion measurements were at noise levels well below $10^{-2} \mathrm{~cm}^{-3}$, and ions must have had energies below $20 \mathrm{eV}$.

[31] The magnetic conjugation at this time was in the southern polar cap, poleward of the cusp. An enhancement of $\mathrm{N}_{\mathrm{e}}(\mathrm{EFW})$ was observed on all Cluster spacecraft, and $3-$ 4 min earlier on SC1 than on the other spacecraft. At this high latitude it is unlikely that this is an expansion of the plasma sheet. A more likely explanation is that a flux tube with higher plasma density, probably originating from the mantle, crossed the Cluster tetrahedron.

\subsection{A Lobe to Plasma Sheet Passage in 2002}

[32] A relatively high plasma density during a passage from the lobe to the plasma sheet allowed for electron plasma density estimates from WHISPER soundings. Good agreement is found between density estimates based on equation (7), WHISPER and PEACE from $~ 0930$ UT until $\sim 0944$ UT (see Figure 17b). During this time period the electron temperature does not exceed a few hundreds $\mathrm{eV}$ (see Figure 17c). After 0944 UT, the electron temperature increases from a few hundreds $\mathrm{eV}$ to $1 \mathrm{keV}$. This is outside the electron temperature range of applicability for equation (7). In this case, electron density values derived from EFW overestimate the true electron density measured by both PEACE and WHISPER, which agree.

\section{Summary}

[33] The potential of the Cluster spacecraft is determined by the current balance between the fraction of the photoelectrons with sufficient energy to escape to the plasma $\left(\mathrm{I}_{\mathrm{phS}}\right)$, and collected ambient electrons $\left(\mathrm{I}_{\mathrm{eS}}\right)$ that depends on electron density and energy. Ion currents can be a few percent of electron currents in the very fast solar wind and in fast plasma flows in the magnetotail during substorms. In view of the limited accuracy of the method for determination of electron density by EFW, ion currents are not included. Electric field probes are given a negative bias current in order to keep them at $1-2 \mathrm{~V}$ relative to their local plasma. This is necessary for electric field measurements and also provides a potential reference for the spacecraft. The technique described in this study is based on calibrations where the plasma density and electron mean energy $\left(\mathrm{eV}_{\mathrm{e}}\right)$ is provided by the relaxation sounder experiment (WHISPER) and the particle experiments (CIS and PEACE). This makes it possible to use spacecraft potential measurements to obtain electron density $\left(\mathrm{N}_{\mathrm{e}}\right)$ with a relatively high time resolution $(0.2 \mathrm{~s})$. This can give information about the fine structure, orientation, and velocity of boundaries, for example at the magnetopause, when using the simultaneous measurements of the four Cluster spacecraft.

[34] For the same electron flux measured in 2001 and in 2006, the spacecraft potential was reduced from 2001 to 2006 due to the reduced solar radiation from near solar maximum to near solar minimum. The electric field probes, used as a potential reference, also shifted relative to their local plasma from $(2.2 \pm 0.2) \mathrm{V}$ in 2001 to $(0.9 \pm 0.2) \mathrm{V}$ in 2004. The spacecraft photoelectron current to the plasma $\left(\mathrm{I}_{\mathrm{phS}}\right)$, for a very positive spacecraft, is determined by EUV and soft $\mathrm{X}$ rays. The probes, biased to be kept at a lower potential, are mainly emitting photoelectrons generated by Lyman alpha radiation. The variation of solar radiation makes it necessary to calibrate the spacecraft potential technique on a yearly basis.

[35] Numerical calculations of the potential distribution around Cluster [Cully et al., 2007] have demonstrated that the potential near the probes is approximately $19 \%$ of the spacecraft potential. This has been taken into account when using the measured potential difference between the spacecraft and the probes $\left(\mathrm{V}_{\mathrm{s}}-\mathrm{V}_{\mathrm{p}}\right)$ to calculate the real spacecraft potential $\left(\mathrm{V}_{\mathrm{s}}-\mathrm{V}_{0 \mathrm{~s}}\right)>\left(\mathrm{V}_{\mathrm{s}}-\mathrm{V}_{\mathrm{p}}\right)$. This will be of interest for particle experimenters, for example when $\left(\mathrm{V}_{\mathrm{s}}-\mathrm{V}_{\mathrm{p}}\right)$ is measured at $40 \mathrm{~V},\left(\mathrm{~V}_{\mathrm{s}}-\mathrm{V}_{0 \mathrm{~s}}\right)$ is approximately equal to $50 \mathrm{~V}$.

[36] The main aim of this study is to determine the electron density, $\mathrm{N}_{\mathrm{e}}(\mathrm{EFW})$, based on spacecraft potential measurements in a very tenuous plasma where particle experiments will experience difficulties. The approach is to determine $\mathrm{I}_{\mathrm{phS}}$ from the current balance between $\mathrm{I}_{\mathrm{phS}}$ and the collected electron current, $\mathrm{I}_{\mathrm{eS}}$, in the plasma sheet. $\mathrm{I}_{\mathrm{eS}}$ is in this case determined by high-energy electrons with a negligible acceleration in the potential around the spacecraft. EDI has been used to estimate $I_{p h s}$ for very large spacecraft potentials. Once $\mathrm{I}_{\mathrm{phS}}$ is estimated, $\mathrm{N}_{\mathrm{e}}(\mathrm{EFW})$ can be derived from the $\mathrm{I}_{\mathrm{eS}}$ values that balance $\mathrm{I}_{\mathrm{phS}}$ in the lobes where electron energy is comparable to $\mathrm{e}\left(\mathrm{V}_{\mathrm{s}}-\mathrm{V}_{0 \mathrm{~s}}\right)$. $\mathrm{N}_{\mathrm{e}}(\mathrm{EFW})$ versus $\left(\mathrm{V}_{\mathrm{s}}-\mathrm{V}_{\mathrm{os}}\right)$ relations can then be calculated for selected values of the electron mean energy $\left(e V_{e}\right)$. We find that these relations are very similar when $\mathrm{eV}_{\mathrm{e}}$ is in an expected range $(10-100) \mathrm{eV}$ in the lobes. However, the variation from year to year is greater than the variation between an electron temperature at $10 \mathrm{eV}$ or $100 \mathrm{eV}$. Variation of the potential near the probes of a few percent above or below the quoted $19 \%$ of the spacecraft potential, has only a minor influence on $\mathrm{N}_{\mathrm{e}}(\mathrm{EFW})$. For practical reasons $\mathrm{N}_{\mathrm{e}}(\mathrm{EFW})$ versus $\left(\mathrm{V}_{\mathrm{s}}-\mathrm{V}_{0 \mathrm{~s}}\right)$ has been translated to $\mathrm{N}_{\mathrm{e}}(\mathrm{EFW})$ versus $\left(\mathrm{V}_{\mathrm{s}}-\mathrm{V}_{\mathrm{p}}\right)$, where the latter is directly measured on Cluster. Equations for $\mathrm{N}_{\mathrm{e}}(\mathrm{EFW})$ are given for 2001 and 2004 based on calibrations with CIS and PEACE in the plasma sheet. Preliminary equations for $\mathrm{N}_{\mathrm{e}}(\mathrm{EFW})$ have been added for 2002 and 2003 based on assessments of solar radiation data.

[37] Plasma densities derived from spacecraft potential measurements in the lobes show that ion experiments often underestimate the ion density because only ions of energies above $\mathrm{e}\left(\mathrm{V}_{\mathrm{s}}-\mathrm{V}_{0 \mathrm{~s}}\right)$ can be measured. Equations (6)-(9) give minimum values of $\mathrm{N}_{\mathrm{e}}(\mathrm{EFW})$ for minimum values of $\mathrm{I}_{\mathrm{phs}}$. Higher $\mathrm{I}_{\mathrm{phs}}$ values, caused by higher EUV and soft X-ray radiation will lead to $50-100 \%$ higher $\mathrm{N}_{\mathrm{e}}(\mathrm{EFW})$ values than estimated from these equations. Figure 9 indicates that $\mathrm{I}_{\mathrm{phS}}$ may vary on very short as well as daily timescales.

[38] The method described in this paper can possibly be extended for use on Cluster spacecraft with the ASPOC ion emitter operating or the EDI electron drift instrument operating in high current mode but would require a reanalysis along the lines given in this paper leading at least to different numerical values.

\section{Appendix A}

[39] An opportunity to check the value of the maximum photoelectron emission from the probes $\left(\mathrm{I}_{\mathrm{php} 0}\right)$ occurred in a 


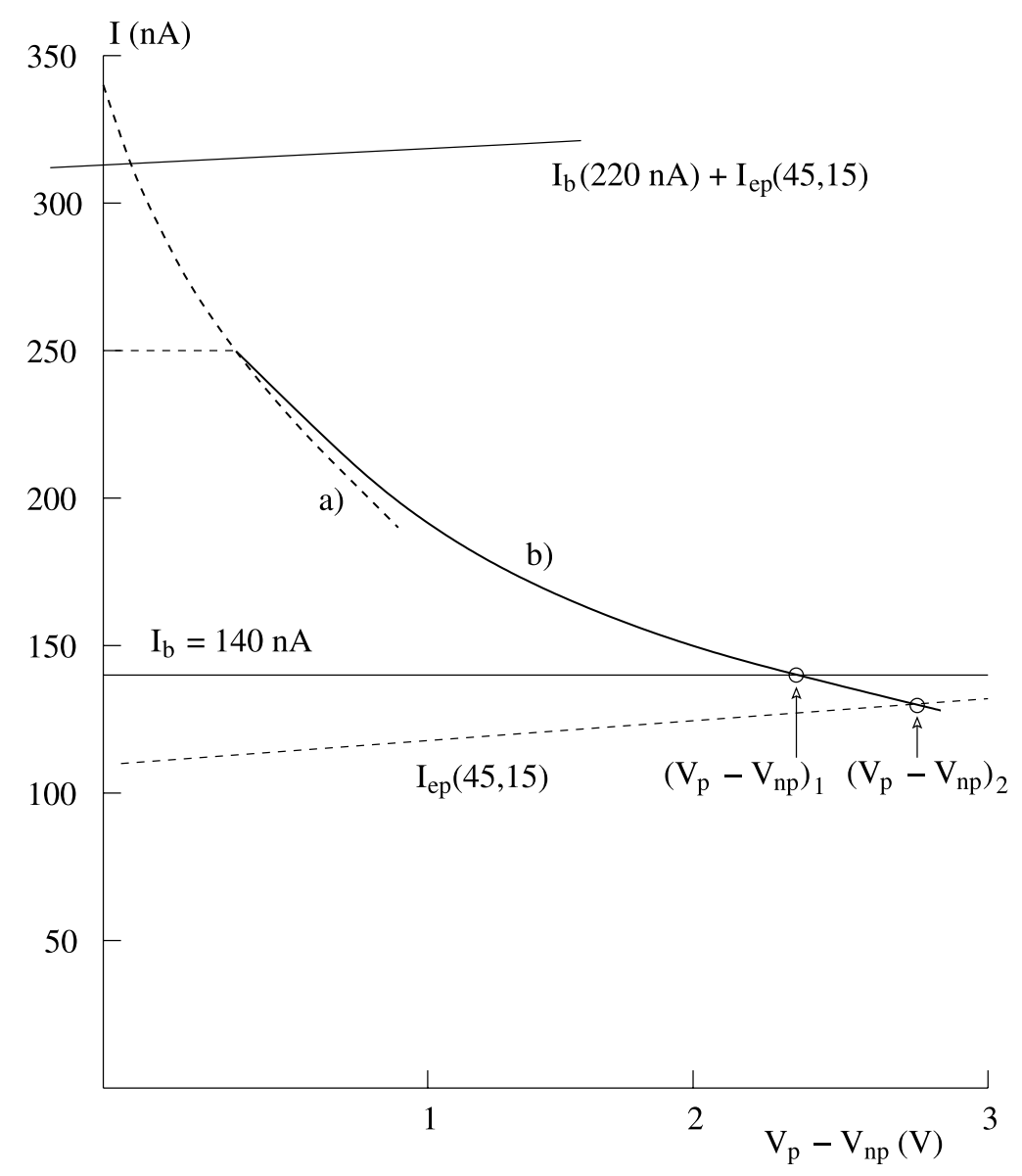

Figure A1. $I_{p h p}$ as a function of $\left(V_{p}-V_{n p}\right)$ for a high density case in the solar wind in $2001 . I_{b}+$ $\mathrm{I}_{\mathrm{ep}}(45,15)$ is above $300 \mathrm{nA}$, and $\mathrm{I}_{\mathrm{php} 0}$ must at least have this value. The bracket $(45,15)$ stands for $\mathrm{N}_{\mathrm{e}}=45 \mathrm{~cm}^{-3}$ and $\mathrm{V}_{\mathrm{e}}=15 \mathrm{~V}$. Curve $\mathrm{a}$ is an $\mathrm{I}_{\text {php }}$ curve with e-folding energy of photoelectrons of $1.5 \mathrm{eV}$. Curve $\mathrm{b}$ is an extension of curve a based on $\mathrm{I}_{\mathrm{b}}$ variations in a tenuous plasma. For $\mathrm{I}_{\mathrm{b}}=140 \mathrm{nA}$ and $\mathrm{I}_{\mathrm{e}} \ll \mathrm{I}_{\mathrm{b}},\left(\mathrm{V}_{\mathrm{p}}-\mathrm{V}_{\mathrm{np}}\right)_{1}=(2.2 \pm 0.2) \mathrm{V}$. For $\mathrm{I}_{\mathrm{b}}=0$ and $\mathrm{I}_{\mathrm{ep}}=\mathrm{I}_{\mathrm{ep}}(45,15),\left(\mathrm{V}_{\mathrm{p}}-\mathrm{V}_{\mathrm{np}}\right)_{2} \approx 2.7 \mathrm{~V}$ which is close to the measured value of $\left(\mathrm{V}_{\mathrm{p}}-\mathrm{V}_{\mathrm{s}}\right)$.

dense solar wind plasma crossing 19 March 2001, 18101814 UT. WHISPER measured an electron density of $45 \mathrm{~cm}^{-3}$. $\mathrm{I}_{\mathrm{b}}$ was set at $220 \mathrm{nA}$ on one probe pair on $\mathrm{SC} 1$, and for this probe pair $\left(\mathrm{V}_{\mathrm{s}}-\mathrm{V}_{\mathrm{p}}\right)$ was $2.8 \mathrm{~V}$. PEACE measured a mean electron energy of $15 \mathrm{eV}$. From equation (2) we get $\mathrm{I}_{\mathrm{ep} 0}=93 \mathrm{nA}$, and we can consequently conclude that $\mathrm{I}_{\mathrm{php} 0}>\mathrm{I}_{\mathrm{b}}+\mathrm{I}_{\mathrm{ep} 0}=313 \mathrm{nA}$. This is close to the value of $\mathrm{I}_{\mathrm{php} 0}$ observed for the same type of probe on ISEE-1 and Polar at times when these spacecraft were close to solar maximum. We can therefore conclude that $\left(\mathrm{V}_{\mathrm{p}}-\mathrm{V}_{\mathrm{np}}\right)$ must have been very small for the 19 March 2001 case, and $V_{n p}$ was very near $\mathrm{V}_{0 \mathrm{p}}$ in this dense plasma, resulting in $\mathrm{I}_{\mathrm{ep}} \approx$ $\mathrm{I}_{\mathrm{ep} 0}$. Curve a in Figure A1 shows an $\mathrm{I}_{\mathrm{php}}$ curve which agrees with these observations, and in addition uses the result from laboratory measurements that the e-folding energy of photoelectrons for small probe potentials $\left(\mathrm{V}_{\mathrm{p}}-\mathrm{V}_{\mathrm{np}}\right)$ is approximately $1.5 \mathrm{eV}$ [Grard, 1973]. Curve b, from left to right, is the $\mathrm{I}_{\text {php }}$ curve obtained in a tenuous plasma when $\mathrm{I}_{\mathrm{b}}$ in 2001 was stepped from small to larger values, and $\mathrm{I}_{\mathrm{php0}}$ was reached for $\mathrm{I}_{\mathrm{b}} \approx 250 \mathrm{nA}$. A likely explanation is that more probe photoelectrons are pulled to the very positive space- craft in a tenuous plasma. This can act as a voltage bias in addition to the $I_{b}$ current bias, and $I_{p h p 0}$ will be reached for $\mathrm{I}_{\mathrm{b}}<\mathrm{I}_{\mathrm{php0}}$. With this interpretation, curve $\mathrm{b}$ is the extension of curve a for $I_{p h p}$ values smaller than approximately $250 \mathrm{nA}$ as drawn in Figure A1. The current balance between $I_{p h p}$ and $I_{b}=140 n A$ in a tenuous plasma results in $\left(\mathrm{V}_{\mathrm{p}}-\mathrm{V}_{\mathrm{np}}\right)=(2.2 \pm 0.2) \mathrm{V}$. For a plasma with $\mathrm{N}_{\mathrm{e}}=$ $45 \mathrm{~cm}^{-3}$ and $\mathrm{V}_{\mathrm{e}}=15 \mathrm{~V}$, marked $(45,15)$ in Figure A1, and $\mathrm{I}_{\mathrm{b}}=0$, a potential $\left(\mathrm{V}_{\mathrm{p}}-\mathrm{V}_{\mathrm{np}}\right)_{2}$ of approximately $2.5 \mathrm{~V}$ will be achieved. This is close to the observed value of $\left(\mathrm{V}_{\mathrm{s}}-\mathrm{V}_{\mathrm{p}}\right)=2.8 \mathrm{~V}$ and demonstrates that an unbiased probe and the spacecraft comes to similar potentials in this plasma $\left(\lambda_{\mathrm{D}} \approx 4 \mathrm{~m}\right)$.

[40] A similar determination of $\mathrm{I}_{\mathrm{php}}$ has been carried out for a dense plasma in the solar wind crossing on 5 April 2006 with $\mathrm{N}_{\mathrm{e}}(\mathrm{WHI})=51 \mathrm{~cm}^{-3}$. No electron temperature data is available for this day. It is assumed that the solar wind electron energy was in the range $(10-20) \mathrm{eV} . \mathrm{I}_{\mathrm{php} 0}$ was consequently estimated to be in the range 230-260 nA or possibly slightly higher. Figure A2 shows the $I_{p h p}$ curve for 2006, and $\left(\mathrm{V}_{\mathrm{p}}-\mathrm{V}_{\mathrm{np}}\right)_{1}$ in a tenuous plasma and 


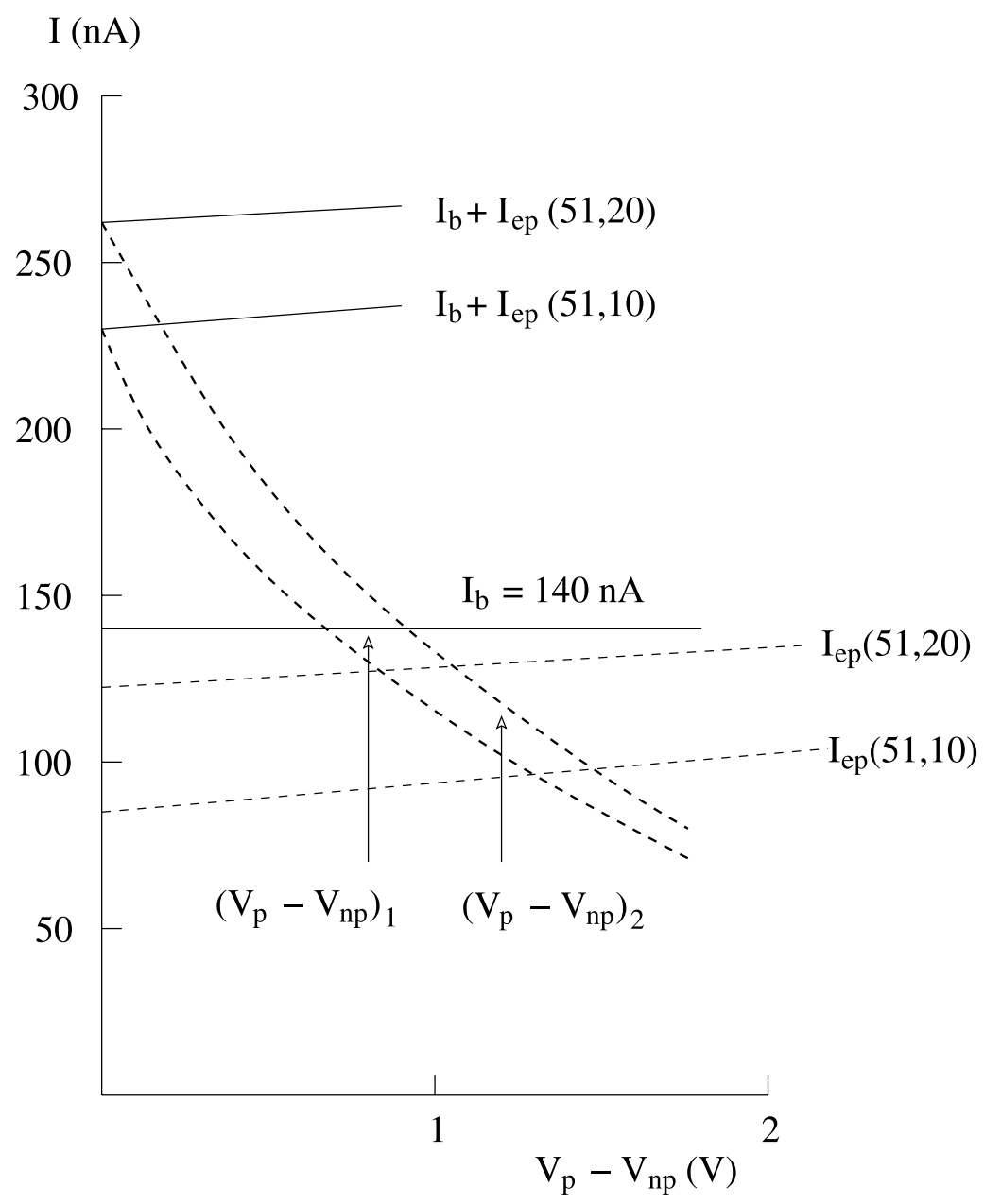

Figure A2. $\mathrm{I}_{\mathrm{php}}$ as a function of $\left(\mathrm{V}_{\mathrm{p}}-\mathrm{V}_{\mathrm{np}}\right)$ in 2006. For $\mathrm{I}_{\mathrm{b}}=140 \mathrm{nA}$ and $\mathrm{I}_{\mathrm{e}} \ll \mathrm{I}_{\mathrm{b}},\left(\mathrm{V}_{\mathrm{p}}-\mathrm{V}_{\mathrm{np}}\right)_{1}=(0.9 \pm$ $0.2) \mathrm{V}$. See text for discussion about $\left(\mathrm{V}_{\mathrm{p}}-\mathrm{V}_{\mathrm{np}}\right)_{2}$.

$\mathrm{I}_{\mathrm{b}}=140 \mathrm{nA}$ to be $(0.9 \pm 0.2) \mathrm{V} \cdot\left(\mathrm{V}_{\mathrm{p}}-\mathrm{V}_{\mathrm{np}}\right)_{2}$ is more uncertain because of missing electron temperature information. However, values of 0.9 to $1.4 \mathrm{~V}$ can be compared to the measured value $\left(\mathrm{V}_{\mathrm{s}}-\mathrm{V}_{\mathrm{p}}\right)=1.6 \mathrm{~V}$. The difference can be due to reduced electron collection to the spacecraft for a more dense plasma and/or slightly different photoelectron emission properties of probes and spacecraft.

\section{Appendix B}

[41] The ambient electron current to the spacecraft body and booms $\left(\mathrm{I}_{\mathrm{eS}}\right)$ will always be much larger than the ambient electrons collected by the much smaller probe systems. However, the situation is different for the photoelectrons. The emission to the plasma from the spacecraft body and booms will drop with an increasing spacecraft potential. The probes, the preamp boxes, and the guards are controlled to be close to their local plasma potential and will to a certain degree maintain their current of photoelectrons escaping to the plasma. For very large spacecraft potentials, this current may be comparable to $\mathrm{I}_{\mathrm{phs}}$, the current of escaping photoelectrons from the spacecraft body and booms to the plasma. The total photoelectron current from the spacecraft and the four electric field antennas can be written:

$$
\mathrm{I}_{\text {phS }}=\mathrm{I}_{\text {phs }}+4\left(\mathrm{f}_{\mathrm{p}} \mathrm{I}_{\text {php }}+\mathrm{f}_{\mathrm{a}} \mathrm{I}_{\text {pha }}\right)
$$

The spacecraft photoelectron characteristic for the complete spacecraft, including the four probe systems, is then $\mathrm{I}_{\mathrm{phS}}$ as a function of $\left(\mathrm{V}_{\mathrm{s}}-\mathrm{V}_{0 \mathrm{~s}}\right)$.

[42] Acknowledgments. We want to thank Philippe Escoubet for discussions and assistance in evaluating this paper. Part of this work was carried out under the auspices of the ESTEC Faculty visiting scientist program.

[43] Amitava Bhattacharjee thanks Jean-Jacques Berthelier and another reviewer for their assistance in evaluating this paper.

\section{References}

Brace, L. H., W. R. Hoegy, and R. Theis (1988), Solar EUV measurements at Venus based on photoelectron emission from Pioneer Venus Langmuir probe, J. Geophys. Res., 93, 7282-7296, doi:10.1029/ JA093iA07p07282.

Cully, C. M., R. E. Ergun, and A. I. Eriksson (2007), Electrostatic structure around spacecraft in tenuous plasmas, J. Geophys. Res., 112, A09211, doi:10.1029/2007JA012269.

Décréau, P. M. E., P. Fergeau, V. Krasnosels'kikh, M. Lévêque, P. Martin, O. Randriamboarison, F. X. Sené, J. G. Trotignon, P. Canu, and P. B. 
Mögensen (1997), Whisper, a resonance sounder and wave analyser: Performance and perspectives for the Cluster mission, Space Sci. Rev., 79, 157-193, doi:10.023/A:1004931326404.

Eriksson, A. I., et al. (2006), Electric field measurements on Cluster: comparing the double probe and electron drift techniques, Ann. Geophys., 24, $275-289$.

Escoubet, C. P., A. Pedersen, R. Schmidt, and P.-A. Lindqvist (1997), Density in the magnetosphere inferred from the ISEE-1 spacecraft potential, J. Geophys. Res., 102, 17,595-17,609, doi:10.1029/97JA00290.

Grard, R. J. L. (1973), Properties of the satellite photoelectron sheath derived from photoemission laboratory measurements, J. Geophys. Res., 78, 2885-2906, doi:10.1029/JA078i016p02885.

Gustafsson, G., et al. (1997), The electric field experiment for the Cluster mission, Space Sci. Rev., 79, 137-156, doi:10.1023/A:1004975108657.

Johnstone, A. D., et al. (1997), PEACE, a plasma electron and current experiment, Space Sci. Rev., 79, 351 - 398, doi:10.1023/A:1004938001388.

Laakso, H., and A. Pedersen (1998), Ambient electron density derived from differential potential measurements, in Measurement Techniques in Space Plasmas: Fields, Geophys. Monogr. Ser., vol. 102, edited by J. Borovsky, R. Pfaff, and D. Young, pp. 73-78, AGU, Washington, D. C.

Laakso, H., R. Pfaff, and P. Janhunen (2002), Polar observations of electron density distribution in the Earth's magnetosphere. Density Profiles, Ann. Geophys., 20(11), 1725-1735.

Laframboise, J. G., and L. J. Sonmor (1993), Current collection by probes and electrodes in space magnetoplasmas: A review, J. Geophys. Res., 98, 337-357, doi:10.1029/92JA00839.

Mott-Smith, J. M., and I. Langmuir (1926), The theory of collectors in gaseous discharges, Phys. Rev., 28, 727-763, doi:10.1103/PhysRev.28.727.

Nakagawa, T., T. Ishii, K. Tsuruda, H. Hayakawa, and T. Mukai (2000), Net current density of photoelectrons emitted from the surface of the GEOTAIL spacecraft, Earth Planets Space, 52, 283-292.

Paschmann, G., et al. (2001), The electron drift instrument on Cluster: Overview of first results, Ann. Geophys., 19, 1273-1288.

Pedersen, A. (1995), Solar wind and magnetosphere plasma diagnostics by spacecraft electrostatic potential measurements, Ann. Geophys., 13, 118-121, doi:10.1007/s00585-995-0118-8.

Pedersen, A., F. Mozer, and G. Gustafsson (1998), Electric field measurements in a tenuous plasma with spherical double probes, in Measurement Techniques in Space Plasmas: Fields, Geophys. Monogr. Ser., vol. 103, edited by R. F. Pfaff, J. E. Borovsky, and D. T. Young, pp. 1-12, AGU, Washington, D. C.

Pedersen, A., P. Decréau, C. P. Escoubet, G. Gustafsson, H. Laakso, P.-A. Lindqvist, B. Lybekk, A. Masson, F. S. Mozer, and A. Vaivads (2001), Four-point high time resolution information on electron densities by the electric field experiment (EFW) on Cluster, Ann. Geophys., 19, $1491-1504$.

Rème, H., et al. (2001), First multispacecraft ion measurements in and near the Earth's magnetosphere with identical Cluster ion spectrometry (CIS) experiments, Ann. Geophys., 19, 1303-1354.
Scudder, J. D., X. Cao, and F. Mozer (2000), Photoemission currentspacecraft voltage relation: Key to routine quantitative low energy plasma measurements, J. Geophys. Res., 105, 21,281-21,294, doi:10.1029/1999JA900423.

Szita, S., A. N. Fazakerly, P. J. Carter, A. M. James, P. Travnicek, G. Watson, M. André, A. Eriksson, and K. Torkar (2001), Cluster PEACE observations of electrons of spacecraft origin, Ann. Geophys., 19, 1721-1730.

Thiébault, B., A. Hilgers, A. Masson, C. P. Escoubet, and H. Laakso (2006), Simulation of the Cluster-Spacecraft Floating Probe Potential, IEEE Trans. Plasma Sci. IEEE Nucl. Plasma Sci. Soc., 34(5), 2078-2083, doi:10.1109/TPS.2006.883407.

Torkar, K., et al. (2001), Active spacecraft potential control for Cluster implementation and first results, Ann. Geophys., 19, 1289-1302.

Torkar, K., M. Fehringer, C. P. Escoubet, M. André, A. Pedersen, K. R. Svenes, and P. M. E. Décreéau (2005), Analysis of Cluster spacecraft potential during active control, Adv. Space Res., 36, 1922-1927, doi:10.1016/j.asr.2005.01.110.

M. André and A. Eriksson, Swedish Institute of Space Physics, Uppsala Division, Box 537, SE-751 21 Uppsala, Sweden. (mats.andre@irfu.se; anders.eriksson@irfu.se)

I. Dandouras and J.-A. Sauvaud, CESR/CNRS, 9 Avenue du Colonel Roche, B. P. 4346, F-31028 Toulouse CEDEX 4, France. (iannis.dandouras@cesr.fr; jean-andre.sauvaud@cesr.fr)

P. M. E. Décréau, Laboratoire de Physique et Chimie de l'Environnement LPCE/CNRS, 3A, Avenue de la Recherche Scientifique, F-45071 Orléans Cedex 2, France. (pdecreau@cnrs-orleans.fr)

A. Fazakerley, Department of Physics, Mullard Space Science Laboratory, University College London, Dorking, UK. (anf@mssl.ucl.ac.uk)

P.-A. Lindqvist, Division of Plasma Physics, Alfven Laboratory, Royal Institute of Technology, S-10044 Stockholm, Sweden. (lindqvist@ plasma.kth.se)

B. Lybekk and A. Pedersen, Department of Physics, University of Oslo, P. O. Box 1048, Blindern, N-0316 Oslo, Norway. (bjorn.lybekk@fys.uio.no; arne.pedersen@fys.uio.no)

A. Masson and M. Taylor, RSSD, ESTEC, Postbus 299, Keplerlaan, 1 NL-2200 AG Noordwijk, Netherlands. (arnaud.masson@esa.int; mtaylor@ rssd.esa.int)

F. S. Mozer, Space Science Laboratory, University of California, Berkeley, Berkeley, CA 94720, USA. (fmozer@ssl.berkeley.edu)

G. Paschmann, MPI fur Extraterrestrische Physik, Giessenbachstrasse, D-85748 Garching, Germany. (goetz.paschmann@mpe.mpg.de)

K. R. Svenes, Division of Electronics, Norwegian Defence Research Establishment, P. O. Box 25, N-2007 Kjeller, Norway. (knut.svenes@ffi.no) K. Torkar, Space Research Institute, Austrian Academy of Sciences, Schmiedlstrasse 6, A-8042 Graz, Austria. (klaus.torkar@oeaw.ac.at)

E. Whipple, Geophysics Department, c/o Space Physics Group, University of Washington, Seattle, WA 98195, USA. (whipple@geophys. washington.edu) 